\title{
State of the art of bioimplants manufacturing: part I
}

\author{
Cheng-Wei Kang ${ }^{1}$ Feng-Zhou Fang ${ }^{1,2}$
}

Received: 14 November 2017 / Accepted: 20 December 2017/Published online: 20 January 2018

(C) The Author(s) 2018. This article is an open access publication

\begin{abstract}
Bioimplants are becoming increasingly important in the modern society due to the fact of an aging population and associated issues of osteoporosis and osteoarthritis. The manufacturing of bioimplants involves an understanding of both mechanical engineering and biomedical science to produce biocompatible products with adequate lifespans. A suitable selection of materials is the prerequisite for a long-term and reliable service of the bioimplants, which relies highly on the comprehensive understanding of the material properties. In this paper, most biomaterials used for bioimplants are reviewed. The typical manufacturing processes are discussed in order to provide a perspective on the development of manufacturing fundamentals and latest technologies. The review also contains a discussion on the current measurement and evaluation constraints of the finished bioimplant products. Potential future research areas are presented at the end of this paper.
\end{abstract}

Keywords Bioimplant · Precision manufacturing · Precision metrology $\cdot$ Evaluation

Feng-Zhou Fang

fengzhou.fang@ucd.ie

1 Centre of MicroNano Manufacturing Technology (MNMTDublin), University College Dublin, Dublin, Ireland

2 State Key Laboratory of Precision Measuring Technology and Instruments, Centre of MicroNano Manufacturing Technology, Tianjin University, Tianjin 300072, People's Republic of China

\section{Introduction}

Bioimplants are of immense significance in improving the longevity and quality of human life. They first appeared as early as four millennia ago when both the Egyptians and Romans used wooden toe replacements and gold for dental applications [1]. However, it was not until the late 18th century that this practice was systematized in the science of implantology [2]. In modern society, it was estimated that about $90 \%$ of the people over 40 years old suffered from degenerative and inflammatory diseases, which led to immobility and unbearable pain. Apart from elderly people, young and active people like athletes are likely facing the same scenario due to the fracture and excessive strain. Various bioimplants have been developed to appease the rapidly increasing requirements for replacing and assisting natural tissue in the human body.

The evolution of bioimplant manufacturing is closely linked to the development of biomaterials. In fact, the field of biomaterials has been receiving substantial attention since 1969, when the world's first summit about biomaterials was held at Clemson University [3]. In the following decades, the study of biomaterials constantly expanded and evolved. The selection of biomaterials for implantation cannot be only based on the traditional cognition of using hard materials with high elastic modulus and low friction coefficient. It is also crucially relied on the proposed application. The interaction between implants and biological tissues should also be taken into consideration. Hence, reviewing the properties of biomaterials is not only fundamental for selecting a proper material for a specific application but also contributes to choosing the right manufacturing process.

The expansion of the bioimplants market has brought new challenges to the product quality and manufacturing 
efficiency. However, the limitations of conventional fabrication processes are becoming more and more apparent in fulfilling the strict requirements of bioimplants regarding the precision, complex structure and novel materials. Although recent research developments in the processing technologies realized the manufacturing of very sophisticated bioimplants, most of the techniques are tentative and immature.

For the complete manufacturing chain, evaluations are of equal importance to the fabrication as it identifies the potential failure mechanisms and hence guarantees a successful application. In fact, the increasing number of implanted biocomponents into the human body has sharply focused researchers' attention to measurement and evaluation, from which a more direct performance assessment and the cause of failure of the bioimplants can be obtained. Multi-functional evaluation and characterization techniques are required for a fast and reliable inspection for the final product acceptance.

The objective of this review is to present the progress and development of orthopaedic bioimplant manufacturing, as well as the research challenges and perspectives. It should be of value to researchers who are interested in the state of the art of bioimplants manufacturing.

\section{Material selection}

An appropriate selection of the materials in the biomedical applications is critical for the long-term success of implants. Accepted biomaterials must meet the following requirements: (i) Biocompatibility. The biocompatibility is always the foremost consideration for implant material selection. The chosen materials must be non-toxic to the human body, so inflammatory or allergic reactions would not be triggered after implantation. (ii) Corrosion and wear resistance. The longevity of implants is particularly determined by the material corrosion and wear. It was reported that the corrosion and wear of implanted materials might lead to sensitivity reactions within human body [4] and also had potential risks in generating local tumours [5]. In addition, malfunctions of the corroded and worn implants would be caused after a long-term service [6]. Considering that the corrosion and wear of implant materials could be accelerated in practical uses due to the more complicated chemical and physical conditions in human body, biomaterials have typically high demands on the resistance to corrosion and wear. (iii) Mechanical properties. Skeletal bone implants, such as artificial hip and knee joints, aim to bear patient's body weight [7]. Thus, suitable mechanical properties of biomaterials are needed to minimize the fatigue failure after millions of cyclic loading. (iv) Economic manufacturing. From the industrial point of view, the manufacturing processes are required to be economically viable.

To match the requirements above, biomaterials such as metallic alloys, ceramics and polymers have been used or being investigated. A detailed review of the typical biomaterials is given in the following sections.

\subsection{Stainless steel}

Stainless steel contains a minimum of $10.5 \%$ (mass fraction) chromium and varying amounts of other elements [8], which was first discovered in the early 1990s [9] and quickly became notable for its ease in manufacturing and low cost. In the past century, it has been widely used in many applications such as the construction of exhaust manifolds, surgical instruments, food handling, vehicle decoration, etc. Stainless steel is renowned for holding the longest record for being used as a biomaterial. Of the many grades in stainless steel family, the austenitic 316L stainless steel is the only category that is used for bioimplant applications. This kind of stainless steel is favoured for the inexpensiveness and not exhibiting ferromagnetism. The austenitic structure also offers this grade an excellent toughness, even down to cryogenic temperatures. According to the cytotoxicity evaluation standards, 316L stainless steels exhibit relatively good biocompatibility [10-14]. The first utilization of stainless steel in biological orthopaedics was reported in the 1930s, when Wiles [15, 16] achieved the total hip replacement. In the following decades, this kind of material evoked tremendous scientific interests in the fabrication of bioimplants and presently being used in large quantities by a factor of $10 \%-20 \%$ in the market [17].

As the mechanical properties of stainless steel can be controlled in a wide range, it allows the fabricated products possessing optimal ductility and strength for medical uses. Such characteristic is especially attractive in the bioimplants manufacturing. In general, stainless steel possesses much greater elastic modules (about $200 \mathrm{GPa}$ ) than human bones (10-30 GPa) [14]. The relatively high ultimate tensile strength and fracture toughness guarantee a satisfactory mechanical performance, as the material can bear significant loads and undergo sufficient plastic deformation before failure [13, 18]. Nevertheless, the mechanical working conditions inside a living body greatly differ from the external environment. Specifically, skeletal bones suffer cyclic loading in the course of patients walking. The estimated step number of a patient over 20 years is over $1 \times 10^{7}$ cycles [7], such cyclic loading may fracture the material below its ultimate tensile strength or yield strength [18]. In fact, stainless steel implants typically subject to fatigue damage as its fatigue strength is relatively low [19-21]. Therefore, the stainless steel is now mainly being used in short-term implant devices. 
Another reason for the short service period of stainless steel is that the material is not sufficiently resistant to corrosion. It was reported that the initiation of fatigue cracks in stainless steel was closely correlated to the corrosion pits [22, 23]. In a long-term application, corrosion would not only degrade the implant mechanical function but also be likely to release ions such as iron, chromium, nickel and molybdenum to human body [24-26]. Although there is no report on the adverse effects induced by iron ions released from stainless steel implants, the excess of other tracer elements may increase the risk of eliciting allergy reactions or toxic effects [25]. Thereinto, $\mathrm{Ni}$ is a typical high-risk element from the perspective of metal toxicity problems [17]. It is worth noting that the extent of corrosion in $316 \mathrm{~L}$ stainless steel based bioimplants is unrelated to either alloy composition or the implantation duration [4].

Wear of the stainless steel based bioimplants is recognized as another major clinical issue. It may lead to implant loosening, along with adverse cellular responses and inflammation [18]. A recent achievement in grain refinement of metallic materials allowed the enhancement of the material properties and an improved sliding wear resistance was presented [27].

In general, due to its low fabrication cost and satisfactory biocompatibility, stainless steel still plays an important role in implant applications at the stage. However, the low fatigue strength, as well as poor corrosion and wear resistance, confines stainless steel to temporary devices. To maintain its prevail role in implant applications, special fabrication methods for producing nickel-free, high-nitrogen and ultra fine-grained stainless steels are required.

\subsection{Cobalt-based alloy}

The first adaption of cobalt-based alloy in biomedical implantation was reported in 1936 for hip arthroplasty [28]. In the following ten years, its medical applications in orthopaedics were significantly expanded and notable successes were achieved [8, 18]. Based on the composition, biomedical Co-based alloys are typically categorized into two groups. One is Co-Cr-Mo alloy, which contains $27 \%-$ $30 \% \mathrm{Cr}$ and 5\%-7\% Mo. Recently, with the longevity expectancy increased to more than 20 years, this material tends to be extensively employed as structural materials in permanent bioimplants. For instance, the Co-Cr-Mo alloy with an ultra-high molecular weight polyethylene as a lining is currently the commonest match of prosthetic knees and ankles [18, 29]. Co-Ni-Cr-Mo is another type of cobalt alloy, whose composition includes Ni (33\%-37\%), $\mathrm{Cr}(19 \%-21 \%)$ and Mo $(9 \%-11 \%)$. It came into use in the biomedical field later than Co-Cr-Mo and was mainly wrought before employed in making heavy load-bearing joints, such as the stems of prostheses [8, 29, 30].

Cobalt alloys have excellent biocompatibility in bulk form, which is closely related to its satisfactory resistance to corrosion [18, 31]. Numerous researchers have revealed that cobalt alloys are highly corrosion resistant even in chloride-rich environments. It is believed that the passive oxide layers formed spontaneously on the alloy surface are responsible for such characteristics. The layers serve as barriers in corrosive environments and thus hinder the corrosion process [30, 32-34]. X-ray photoelectron spectroscopy (XPS) analysis shows that the formation of oxide layers is largely attributable to the high $\mathrm{Cr}$ content. Mo and $\mathrm{Ni}$ also played a similar but insignificant role. Although the major alloying compositions such as $\mathrm{Co}, \mathrm{Cr}$, Mo and $\mathrm{Ni}$ are all essential trace elements in the human body, they would be biologically toxic when excessive, and result in damaging kidney, liver, lungs and blood cells [35-39]. Thus, the release of particles or ions caused by material fatigue and aseptic loosening is a big concern for Co-alloy biomaterials [18].

In comparison to stainless steel, cobalt-based alloys have a longer lifespan and less likely to experience fatigue fracture [30]. This is due to the crystallographic nature of the major element, cobalt, ensures the alloy possesses superior mechanical properties [18]. The elastic modulus and ultimate tensile strength of the material are $230 \mathrm{GPa}$ and 430-1028 MPa, respectively, which is almost 10 times higher than that of human cortical bones [30, 35]. Such outstanding mechanical properties make cobalt alloys suitable for a wide variety of orthopaedic applications. However, an obvious disadvantage brought by the high elastic modulus is the "stress shielding effect". Specifically, the replaced implant may bear basically all the load around the site and prevent the needed stress being transferred to the bones nearby. This effect would gradually weaken the stimulus for bone remodelling and therefore lead to bone atrophy [18, 40]. Moreover, the high costs involved in manufacturing have put Co-based alloys at another disadvantage when it comes to medical market. Although imperfect, cobalt alloys are still regarded as a favourite metallic implant material in joint bearing applications [18].

\subsection{Titanium-based alloy}

Titanium and its alloys are favourable biomaterials due to the combination of several remarkable characteristics, such as low density, high strength, excellent biocompatibility and ideal mechanical properties [1, 29, 41]. The demand of Ti-alloys in medical applications has surged since the 1970s, and the upward trend of employing them as bioimplant materials is likely to continue. Of all the 
titanium-based products, Ti-6Al-4V is the most commonly used material which takes up about $45 \%$ of the total production [18]. Interestingly, the preliminary purpose of developing Ti-6Al-4V alloy was for aerospace applications, while its attractive biocompatibility led it into the field of biomaterials [3, 42].

The element titanium is non-existent in the human body and its biological role is unclear [43], but what is certain is that titanium is non-toxic. It has been well reported that titanium is totally inert to body environment [29, 44]. If titanium was excessive in a living body, excretion would take place without any absorption or digestion [45]. The inertness seems to make Ti and Ti-alloy a perfect material for implants. However, ill effects such as osteomalacia, allergic reaction and peripheral neuropathy were still found in Ti-alloy implanted bodies, which were likely due to the release of aluminium and vanadium from the alloy $[1,3,46]$. The development of new generation of Ti-alloys ( $\beta$-titanium alloys) is now in progress. Attempts of replacing $\mathrm{Al}$ and $\mathrm{V}$ by relatively safer elements such as Mo, Ta, Nb and Zr have been carried out [47, 48]. However, it should be noted that long-term follow-up investigation data are absent [18]. As mentioned, the biocompatibility of an implanting material is highly depended on its corrosion resistance. There is no doubt that $\mathrm{Ti}$ and Ti-based alloys are facile princeps in this regard. Similar to cobalt-based alloys, by virtue of a passive oxide film, the corrosion resistance of Ti-alloys is more than an order of magnitude greater than that of stainless steels $[1,18,29]$. The major difference is that due to the intrinsic properties of matrix element titanium, the corrosion resistance of Ti-alloy does not need to be enhanced through alloying [18].

The mechanical properties of Ti-based alloys are influenced by the variation of the interstitial and impurity levels [18]. In another case, the second generation of Ti-based alloy Ti-Nb-Zr-Ta, also known as TNZT system, realized the lowest elastic modules of any metallic alloy biomaterials with the help of new alternative alloying elements $[47,49]$. It is worth noting that although the elastic modulus of Ti alloys is lower than Co-based alloys, the stress shielding effect remains an issue as the effect can only be reduced but impossible to be prevented [1]. In terms of the ultimate tensile stress, the values tested from $\beta$-titanium alloys are comparable with that from stainless steels but lower than Co-based alloys [8, 18]. Ti-alloys have been proved to possess greater wear resistance than Co-alloys according to hip joint simulation tests [42]. However, externally applied stresses may damage the unstable oxide layer, and hence generate hard oxide particles in the human body. The debris would in turn further break down the oxide layer and cause more severe surface damages to the implants. Therefore, Ti-based alloys are more recommended to be applied as components of modular constraints, rather than articulate against other materials [18].

A comparison of metallic biomaterials of stainless steel, cobalt-based alloys, titanium and Ti-based alloys was summarized by Long and Rack [42]. The characteristics and utilizations of these metallic materials can be seen in Table 1. The information provided a clear perspective of why $\mathrm{Ti}$ and Ti-alloys are regarded as the most promising metallic biomaterial to date.

\subsection{Polymer}

Due to the ease of manufacturability, adequate mechanical properties and low cost, polymers are now frequently applied in biomedical uses. One typical application of polymer in bio-implantology is being used as acetabular cups. In incongruent joints such as knee and ankle, stress concentration is easy to occur at the interface between two incongruent surfaces and hence damage the neighbouring bones. The existence of cartilage layers and synovial fluid in human body plays a predominant role in decreasing such heterogeneous stresses. However, for artificial joints made by brittle metallic materials, the impact of residual stresses could be significant and is hard to be removed. Therefore, researchers turned their attention to polymer materials. In the 1960s, Charnley [50] first realized low-friction arthroplasty with the help of a small-diameter metallic femoral head articulating with a polymeric acetabular cup. Such design immediately drew enormous attention for artificial joints manufacturing. After all these years, this concept is still retained in total joint replacement arthroplasty [42]. Although the mechanical feature of low elastic modulus helps polymer biomaterials to avoid stress-shielding effect after implanting, the relatively low strength hinders their potential application in hard tissues.

Polymers are also favoured for their flexibility as they can be fabricated into various forms to meet demands of different applications, such as solids, fibres, films and fabrics. But for the same reason, the weakness of the material makes its wear behaviour unsatisfactory [51]. Therefore, surface modifications of polymer biomaterials are usually evolved to enhance the functionality before putting into use [52].

\subsection{Ceramics}

The exploitation of ceramics as biomaterials started in the 1970s [53]. The unique properties such as excellent biocompatibility have made ceramic a favourable material for bone repair and joints substitutions [53-55]. Based on the reaction level in a living body, bioceramics are usually categorized into three types, namely, bioinert ceramics, 
Table 1 Characteristics of orthopaedic metallic implant materials [42]

\begin{tabular}{|c|c|c|}
\hline Stainless steels & Cobalt-base alloys & Ti\&Ti-base alloys \\
\hline \multicolumn{3}{|l|}{ Designation } \\
\hline \multirow[t]{3}{*}{ ASTM F-138 (“316 LDVM”) } & ASTM F-75 & ASTM F-75 (ISO 5932/II) \\
\hline & ASTM F-799 & ASTM F-136 (ISO 5832/II) \\
\hline & ASTM F-1537 (cast and wrought) & ASTM F-1295 (cast and wrought) \\
\hline \multicolumn{3}{|l|}{ Principal alloying elements $\ \%$ (mass fraction) } \\
\hline $\mathrm{Fe}($ bal.) & Co(bal.) & Ti(bal.) \\
\hline $\operatorname{Cr}(17-20)$ & $\operatorname{Cr}(19-30)$ & $\operatorname{Al}(6)$ \\
\hline $\mathrm{Ni}(12-14)$ & $\operatorname{Mo}(0-10)$ & $\mathrm{V}(4)$ \\
\hline $\operatorname{Mo}(2-4)$ & $\mathrm{Ni}(0-37)$ & $\mathrm{Nb}(7)$ \\
\hline \multicolumn{3}{|l|}{ Advantages } \\
\hline Cost, availability & Wear resistance & Biocompatibility \\
\hline \multirow[t]{3}{*}{ Processing } & Corrosion resistance & Corrosion \\
\hline & Fatigue strength & Minimum modulus \\
\hline & & Fatigue strength \\
\hline \multicolumn{3}{|l|}{ Disadvantages } \\
\hline Long term behaviour & High modulus & Power wear resistance \\
\hline High modulus & Biocompatibility & Low shear strength \\
\hline \multicolumn{3}{|l|}{ Primary utilizations } \\
\hline $\begin{array}{l}\text { Temporary devices (fracture plates, screws, } \\
\text { hip nails) }\end{array}$ & Dentistry castings & $\begin{array}{l}\text { Used in THRs with modular (CoCrMo or ceramic) } \\
\text { femoral heads }\end{array}$ \\
\hline \multirow[t]{2}{*}{ Used for THRs stems in UK (high nitrogen) } & Prostheses stems & Long-term, permanent devices (nails, pacemakers) \\
\hline & $\begin{array}{l}\text { Load-bearing components in TJR } \\
\text { (wrought alloys) }\end{array}$ & \\
\hline
\end{tabular}

bioactive ceramics and bioresorbable ceramics [53, 56]. The bioinert ceramics are basically inert in a human body. This may be due to a thin non-adherent fibrous layer would usually be formed at the interface of ceramic and bone [55]. Such kind of material is valued in joint replacement prostheses because of the excellent durability. The bioactive ceramics refer to the materials that possess osteoconductivity or direct bone-bonding ability, one typical example of this bioceramic is bioglass ${ }^{\circledR}[55,57,58]$. As they would spontaneously induce a biological bonding to the living tissues nearby after implanting, this type of ceramic was widely applied in the coating of metal prostheses [52]. The third category, bioresorbable ceramic, degrades in the host body over time and would be gradually replaced by the regenerated bones [55]. They provide a better control of the biomaterial resorption and bone substitution processes [59]. Tricalcium phosphate and calcite are typical bioresorbable ceramics [59, 60].

Two most well-known representatives of bioinert ceramics are alumina and zirconia $[55,61]$. They are both favoured for the biocompatibility as the chemical compositions are either common ions in the physiological environment or haveminor toxic effect to human bodies [62].
Alumina's increasing popularity lies in the combination of modest fracture toughness, satisfactory wear properties, excellent corrosion resistance and high compression resistance. The high elastic modulus and hardness that are only second to diamond make alumina a tremendous potential for loading bearing systems in artificial joints [53]. After Boutin [63] reported the first employment of a total hip prosthesis with an alumina head and alumina socket in 1971, the expansion of alumina ceramic in clinical uses was enormous in the later decades. Now, alumina bioceramic is most commonly seen in femoral heads in conjunction with a polymer acetabular cup and a metallic femoral stem for hip replacements, as well as wear plates in knee replacements [54, 64]. However, it was necessary to further improve its reliability as slow crack growth was found in alumina ceramic with time in service [65]. Other defects such as low fracture strength, high brittleness, hard to fabricate, etc., also impair its potential uses.

Zirconia is thought to be a good alternative to alumina because it has similar merits as alumina, but possesses substantially higher fracture toughness $[61,66]$. The use of zirconia in the biomedical applications was first introduced by Helmer and Driskell [67]. In 1988, Christel et al. [68] 
illustrated the feasibility of zirconia in manufacturing ball heads for total hip replacement, which subsequently became its main application. Compared to the utilization of alumina in hip prostheses, zirconia bioceramic allows a significant reduction in the diameter of the femoral head, which enables a higher degree of freedom for the mobility of the joint [62]. At present, Tetragonal zirconia polycrystal (TZP) was selected by the ball head manufacturers and only a few cases of clinical failure were reported $[61,69,70]$. Due to the satisfactory fatigue resistance, over 300000 TZP femoral heads have been implanted till 2002 [62]. There is no doubt that this material is experiencing a significant era in its development as bioceramic. Efforts have recently been made to apply zirconia ceramics in the total knee replacement. Nevertheless, such bioceramic is still regarded as a new material in the biomedical field, whether that the failure rate may increase with time passes is yet to know [70,71]. Attention should also be paid to the growth of slow subcritical cracks and the deterioration of toughness with time [62]. Hence, long-term evaluations and further studies are required to optimize its performances in clinical application.

Calcium phosphate ceramic such as hydroxyapatite (HA) is regarded as a good bioceramic for bone substitutes due to its outstanding biocompatibility, low density, chemical stability and structural similarity to bone minerals $[72,73]$. Apart from these material characteristics, the most remarkable feature of HA in the biomedical application is its bone bioactiveness, i.e., it promotes hard tissue ingrowth and osseointegration after being implanted into the human body. Since the concept of biological fixation was proposed in the late 1960s, which suggested that prosthetic components could be firmly bonded to the host bone by ongrowth or ingrowth without using bone cement, HA coatings have been used more and more widely on the metallic biomaterials [74, 75]. In the past half-century, numerous studies have confirmed the enhancement effect on bone tissue ingrowth stimulated by the HA coatings through analyzing the bonding interface between HA and surrounding bone tissues [76, 77]. From the biomedical perspective, such features realize achieving the distinct therapeutic benefit of faster rehabilitation for patients. As the current trend in bioceramic research is improving the material biological properties through exploring the unique advantages of nanotechnology. Research attempts have been made on improving the HA's crystallinity degree and reducing the grain size to nanometric [78]. Compared to conventional HA, synthetic hydroxyapatite with nanoscaled features present a higher surface area and looser crystal-to-crystal bonds, which allows a more homogeneous resorption by osteoclasts [72].

Although the clinical results from HA coating are promising, the poor mechanical properties of HA remain a major concern. Because the bulk HA lacks sufficient tensile strength and the bending strength is lower than $100 \mathrm{MPa}$, mechanical failure is likely to occur after long service time [75]. Furthermore, the significant brittleness of bioceramics hinders their applications in load-bearing implants [78]. This is the main reason why HA is commonly coated onto a metal core or incorporated into polymers as composites. Even though it has been reported that HA-coated metallic bioimplants indeed possess favourable surface bioactivity, the poor ceramic/metal interfacial bonding cannot be ignored as they may trigger severe structure failure [78]. Again, the inferior mechanical properties of HA should take the responsibility of poor coating stability [79]. Great research efforts have been made to enhance the low bonding strength at the HA/metal interface. As the coating methods directly influence the layer adhesion strength and reliability, advances on coating processes are believed to be the key to solve the problem.

\section{Forming processing}

There have been enormous developments regarding bioimplants in recent decades, with the establishment of a variety of fabrication techniques. These techniques may be classified from different stages. In general, there are prefabrication of forming and post-fabrication of surface finishing. Traditional forming processes such as casting, sintering and compression moulding have experienced a sustainable development to be suitable for manufacturing bioimplants with satisfactory properties, along with increased efficiency. Recently, the state of the art forming technologies for bioimplants use various processes which are capable of precise controllability and so conform to the custom design. In the following sections, some of the typical methods for forming orthopaedic implants will be emphatically introduced.

\subsection{Wrought and cast}

At present, commercial metallic orthopaedic joints are mostly fabricated from wrought or cast bar stock [42, 80, 81]. Take Ti and its alloys for examples, wrought products account for around $70 \%$ of the market [82]. By carrying out several melt cycles during the wrought process, hydrogen or other volatiles can be effectively removed and thus realizing high purity [82]. The final shape of the wrought product is fabricated by thermomechanical treating, i.e., cold/hot working plus heat treatment. In this way, desired mechanical properties can be achieved [81]. The wrought Co-Ni-Cr-Mo alloys emerged at the beginning of 21 st century. They showed superior resistance to fatigue and ultimate tensile strength for long-term 
applications [30], and were now widely used for making the stems of prosthes for load-bearing joints, such as the hip and knee.

Casting is particularly popular in the fabrication of commercial Co-Cr-Mo biocomponents [30, 80]. Compared to the wrought process, casting takes shorter working period. Previous studies have revealed that wrought and casted Co alloys are both highly resistant to corrosion and possess similar abrasive wear resistance [30]. However, finer crystals were found in the casted Co alloys than the wrought products [83]. It was reported that the casted Ti6Al-4V alloys with post-treatments exhibited better crack propagation resistance than wrought ones, but inferior in ultimate tensile strength [81]. A study conducted by Jovanović et al. [84] suggested that the hardness and tensile stress of casted titanium alloys could be increased by controlling the cooling rates and annealing temperatures. Lin et al. [85] revealed that the presence of the castinginduced surface/subsurface pores in Ti alloys was the primary cause of the fatigue cracks.

The disadvantages of wrought and cast are obvious. From the economy aspect, high yield losses are associated with wrought and casting processes. In consideration of the working efficiency, both techniques require relatively long product-cycle time and need complex post-treatments. Most importantly, wrought and casted metallic bioimplants possess much higher elastic modulus than living bones, which are liable to the stress shielding effect after implanting [40]. To solve the problems, attempts of introducing a considerable amount of interconnected pores into biomaterials were made by researchers [86]. It was found that the porous implants turned out to be effective in lowering the elastic modulus and hence conducive to matching with the surrounding bones. As a result, recent research efforts are gradually leaning towards developing fabrication technologies with capabilities of producing porous bodies of biomaterials.

\subsection{Powder metallurgy}

Powder metallurgy (PM) is one type of the rapid solidification processes, which enables the products to achieve fine microstructure and isotropic mechanical properties [87]. Conventional PM process, also known as "pressing and sintering process", usually consists of three basic steps. To be specific, blending powders, compacting them into a designed mould, and the final step of sintering [88]. As can be told from the procedure, this technique provides a viable approach for low-cost fabrication by significantly reducing the yield losses. In fact, its capability of nearly waste-free net-shape forming is one of its most attractive characteristics. Meanwhile, the technique offers a precision control of the composite materials, hence good mechanical properties can be achieved [89]. Currently, PM has been applied in many fields to produce relatively homogeneous structures and is typically regarded as a promising technique for fabricating bioimplants. One feature of PM that has drawn particular interest in biomedical engineering is that it can produce combined small and large pores in the implant body by adjusting processing parameters such as powder size, temperature and pressure. From the biomedical implantology perspective, the porous structure would not only decrease the elastic modulus of implant devices to avoid stress shielding effect [40], but also increase the surface area to allow a higher cell seeding efficiency [90]. The bone ingrowth after implantation is therefore promoted [91]. Obviously, The produced bioimplants by PM would realize a better integration between the implants and living environments comparing to wrought and casted products.

The growing demand for PM fabricated 316L stainless steel is contributed from the ease of fabrication and economic advantages [89]. By judiciously controlling the sintering factors such as atmosphere, time and cooling rate, stainless steel with $40 \%-50 \%$ porosity range could be successfully obtained. The achieved porous structure is optimal for biomedical applications since the ideal porosity for new bone ingrowth is between $20 \%$ and $59 \%$. According to the study conducted by Dewidar et al. [92], the mechanical properties of PM fabricated porous $316 \mathrm{~L}$ stainless steel match well with human bones. Nevertheless, the limitation of PM stainless steel is that the porosity can lead to a reduction of corrosion resistance due to the increase of the reaction area $[93,94]$. The feasibility of adding other alloying elements to stainless steel powders to compensate the loss of corrosion resistance has been investigated [89].

The employment of powder metallurgy on titanium and its alloys initiated in the mid-1970s. It was found that the PM technique not only helped to lower the fabrication costs but also produced fine-grained structures that contributed to better fatigue properties [89]. Seah et al. [93] looked into the corrosion behaviour of powder metallurgically fabricated titanium parts. Comparisons substantiated that porous titanium exhibited a much better corrosion resistance than 316L stainless steels. Opposite to the case of 316 L stainless steel, a higher porosity actually enhances the corrosion resistance of $\mathrm{Ti}$. This is because the large and interconnected pore morphology contributes to the supply of oxygen in passivation. Ning and Zhou [95] applied PM to fabricate biocomposites from hydroxyapatite and titanium powders. The combination of favourable bioactivity of HA and satisfactory mechanical properties of Ti metal provides an alternative material for load-bearing implants. In the case of manufacturing Co-Cr-Mo based implants, powder metallurgy offers more advantages when comparing with other near net shape forming techniques such as precise 
casing and hot forging. The tested rigidity of PM fabricated Co-Cr-Mo alloys is greatly lower than the casted ones, which is conducive to the bone restoration processes. Compositing calcium pyrophosphate during PM process is found to be advantageous for enhancing both compression strength and yield point values of Co-Cr-Mo alloys [96]. Another aspect of research in PM is to increase the homogeneity of the sintered products by improving the quality of powders. With this aim in mind, various of techniques such as mechanical alloying, inert gas atomization, hydriding and pulverization were used to produce pre-alloyed powders [97].

However, it should be noted that the present status of manufacturing orthopaedic implants by PM remains some issues, such as the size of the target components are limited by the press capacity, the expenses of compacting is relatively high, pre-treatment of preparing pre-alloyed powders are involved, etc. [89]. Moreover, the following manufacturing processes are usually required for powder metallurgically fabricated biomedical implants to precisely control the surface finish.

\subsection{Additive manufacturing}

The biological system in a human body is complex, where biomechanical properties may vary greatly from bone to bone. For example, the elastic modulus of cortical region of dense bones ranges from $16 \mathrm{GPa}$ to $20 \mathrm{GPa}$, which is an order of magnitude higher than the trabecular bone. It thus can be imagined that notable biomechanical mismatches are likely to occur between the surrounding bones and the newly implanted components with uniform properties. In addition, from the clinical point of view, the biomechanical properties may vary significantly from patient to patient. Therefore, developing a fabrication process that is capable of providing specific constructs for the defect or injury is in a timely fashion.

Additive manufacturing (AM), also known as rapid prototyping (RP) technologies, is a collective name for the fabrication methods that based on the conception of laminate forming. Since it emerged in the 1980s, such technology has become the subject of research in the field of fabrication [78]. Prior to an AM process, 2D slice data were obtained from laminating custom designed 3D structures. Target objects are then created through accumulating layers of material. Unlike many conventional manufacturing processes that remove materials from a stock, AM method forms 3D objects by continually adding materials instead. More recently, it shows enormous potential in producing commercial customized bioimplants. In the following section, two types of AM processes that are available for fabricating orthopaedic implants will be focally discussed.

\subsubsection{Electron beam melting}

Electron beam melting (EBM) is one typical direct layered fabrication method that enables manufacturing complex 3D parts [86]. An illustration of the EBM working system can be seen in Fig. 1. The system consists of two main compartments of electron beam gun and specimen-fabrication. Both compartments were kept in a high vacuum. A thermionic emission gun with tungsten filament is normally employed to produce an electron beam. The target component is built from the bottom by scanning the focused electron beam on specific areas with the assistance of 3DCAD system. A powder rake moves between cassettes with the progress of fabrication, so that new powders can be continuously distributed on the top of the built component after the completion of previous melted layers. Preheating is carried out at low power but high velocity before melting in order to sinter the powders. The sintered particles are necessary to support downward facing surfaces during building and would be efficiently recycled after breaking up by the following shifting process. For more detailed working principles on this technology, do refer to other good reviews and books [98, 99].

The most attractive characteristic of EBM in manufacturing bioimplants is the availability of custom design. Figure 2 shows an example of near-shape femoral components fabricated by EBM [81]. Obviously, a precision

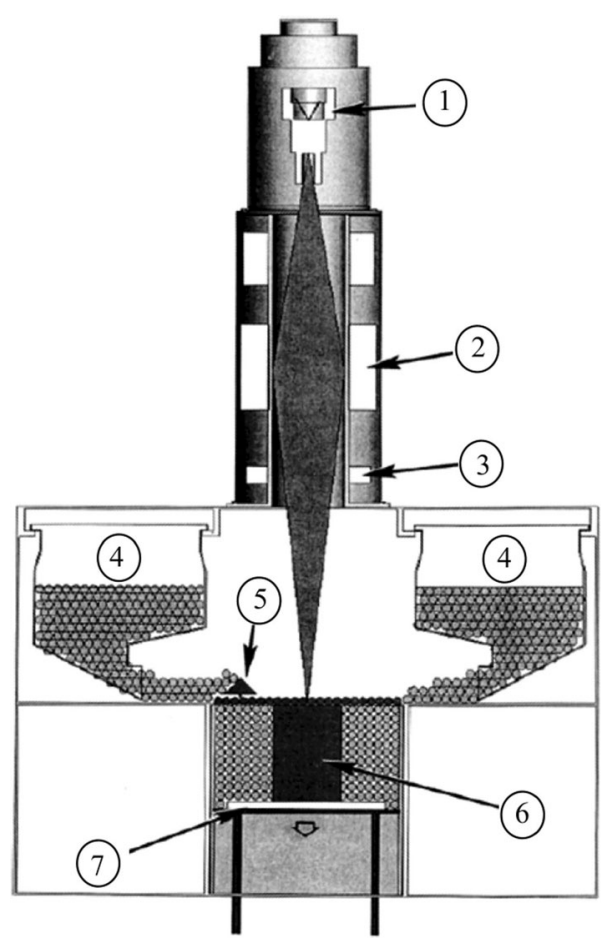

Fig. 1 EBM working system adapted from Ref. [80] ((1) electron gun assembly; (2) focusing lens; (3) deflection coils; (4) powder cassettes; (5) powder layer rake; (6) specimen; (7) build table) 
surface finish machining is required before putting the components into practical uses. Heinl et al. [100] employed EBM to introduce cellular structures to titanium components. The experimental results suggested that the mechanical properties of the components could be well governed by the relative density. Valuable analytical laws between the mechanical properties and relative density were established. In the later stage, the research group adapted different mesh arrays using EBM and successfully fabricated a novel cellular Ti-6Al-4V alloy with similar stiffness to human bones [101]. Similar works were carried out by Harrysson et al. [86] in which they utilized EBM to fabricate hip stems with a lattice structure. The authors demonstrated that the elastic modulus and strength of the stems were predictable if the lattice unit cell size was precisely controlled. Such achievements are believed to be beneficial for providing a better fixation of the bioimplants, as well as a long-term stability.

Some earlier studies have proved the merit of EBM fabrication in enhancing the mechanical properties of workpieces. Murr et al. [80] typically compared biometallic prototypes containing different microstructures of solid, mesh and foam with various densities fabricated in monolithic forms utilizing EBM [80]. Figure 3 shows some testing components in their work. The solid Ti-6Al-4V prototypes produced by EBM exhibited similar mechanical properties to that of commercial wrought ones. However, a phase transition was found in the meshed and foamed samples, which was liable to give a rise to the hardness and strength. On the other hand, all the EBM fabricated Co-CrMo samples with various microstructures appeared to possess superior properties than the standard components. Based on the data analysis of relative dynamic stiffness plotted against relative density, a stress shielding design graph was constructed. The new design permits the meshed and foamed bioimplants to be fabricated with tailored and improved mechanical properties. Such characteristic shows considerable promises for the future manufacturing of orthopaedic implants with compatible bone stiffness. A

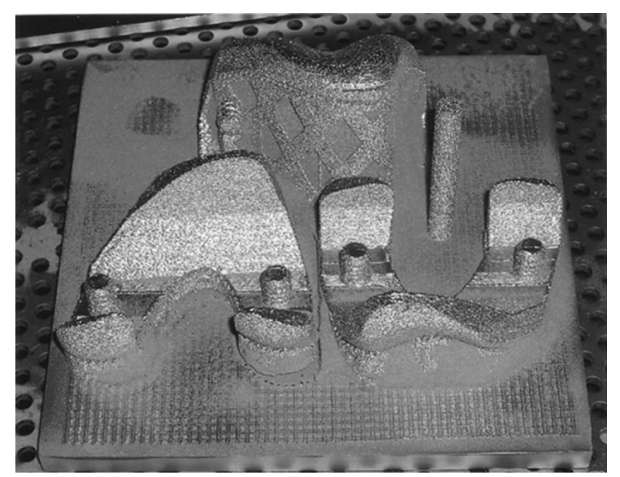

Fig. 2 Typical EBM fabricated femoral components [81] bright prospect of manufacturing patient-specific implant components through EBM can be foreseen.

Apart from the above-mentioned, another advantage of EBM over conventional methods is the economic efficiency. For instance, a standard knee implant machined by traditional manufacturing technologies from bar stocks usually involves $80 \%$ material waste [81]. While the cyclic working system offered by EBM maximizes the waste prevention. In terms of working period, EBM is capable of directly creating a porous surface to benefit the bone ingrowth after implantation. No further surface treatments are required to be taken, and hence avoid lengthy manufacturing times [102].

\subsubsection{Selective laser melting}

Selective laser melting (SLM) is a typical solid freeform fabrication technique which builds components layer-bylayer in a manner similar to EBM. A schematic view of the SLM working system is illustrated in Fig. 4 [81]. An obvious difference to EBM is that, in an SLM process, a laser is employed to selectively fuse and consolidate powders instead of an electron beam. Both benefits and drawbacks of SLM were described by Kruth et al. [103], and the summarization can be found in Table 2 [103]. In the past decades, SLM technique has been already successful in the industries of metallurgy, aviation, aerospace and automation [104]. It extended its application to the field of bio-engineering only at the beginning of 21 st century. In regard to bioimplants manufacturing, SLM is favoured for the notable merits including cost-efficiency, spoke fabrication for an individual patient, ability to adjust mechanical properties and controlling the internal porosity of the objects [105].

Previous SLM works on biomaterials mainly focused on the rapid manufacturing of near-full-density components by reducing the porosity [106-109]. For instance, Xin et al. [108] revealed that SLM fabricated solid Co-Cr alloys exhibited more homogeneous microstructures than these of casted ones. Valid evidences showed that the Co-Cr alloy based oral prostheses prepared by SLM had obvious advantages in surface hardness and corrosion resistance [108]. Liverani et al. [107] manufactured Co-Cr-Mo prosthetic ankles by means of SLM with attempts of maximizing possible density. The subsequent kinematic tests confirmed a suitable functional integrity and a comparable performance to a natural joint motion. Zhang et al. [110] successfully manufactured a Ti-24Nb-4Zr-8Sn alloy based biocomponent of an acetabular cup for the first time using SLM technique [110]. A nearly full density ( $>99 \%)$ was achieved via applying high laser power with a rapid scanning speed. The component showed similar mechanical properties to those fabricated by conventional processes 

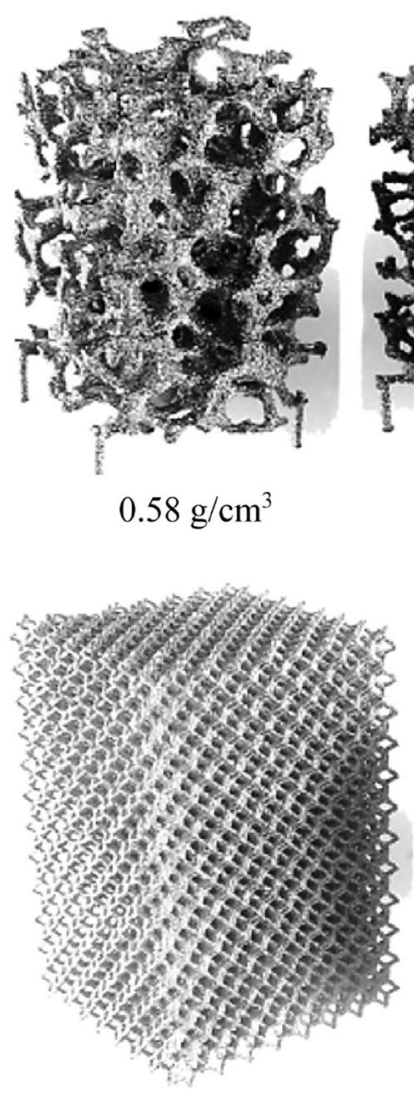

$0.86 \mathrm{~g} / \mathrm{cm}^{3}$

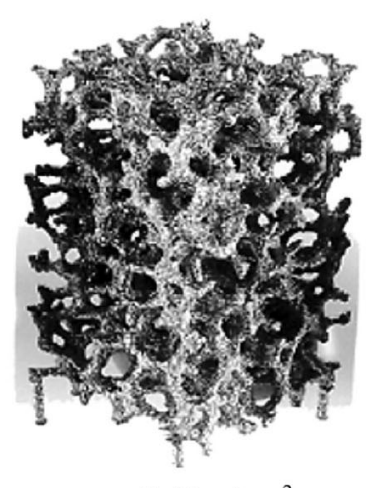

$0.68 \mathrm{~g} / \mathrm{cm}^{3}$

(a)

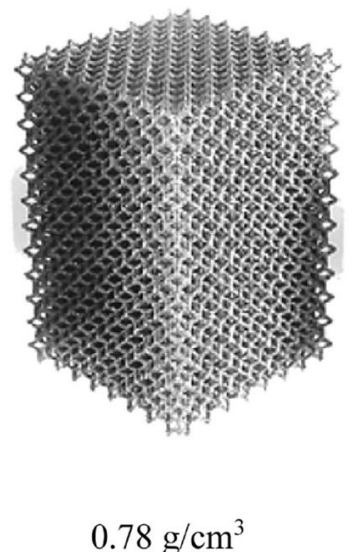

(b)
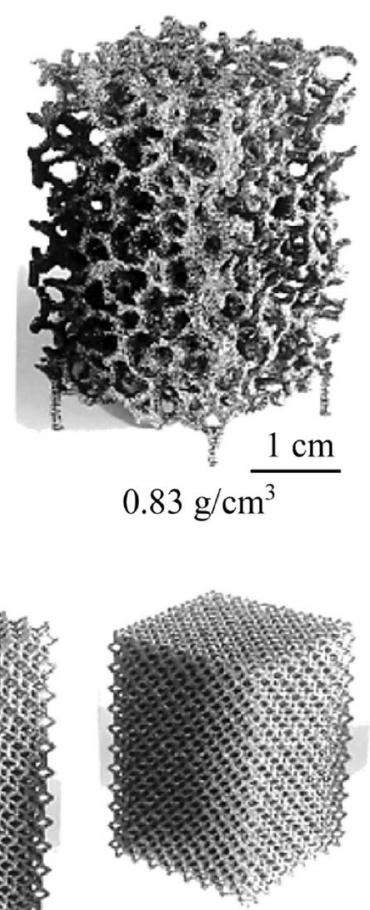

$2 \mathrm{~cm}$

$1.59 \mathrm{~g} / \mathrm{cm}^{3}$

Fig. 3 EBM fabricated Ti-6Al-4V in a foam and $\mathbf{b}$ mesh structures, adapted from Ref. [80]

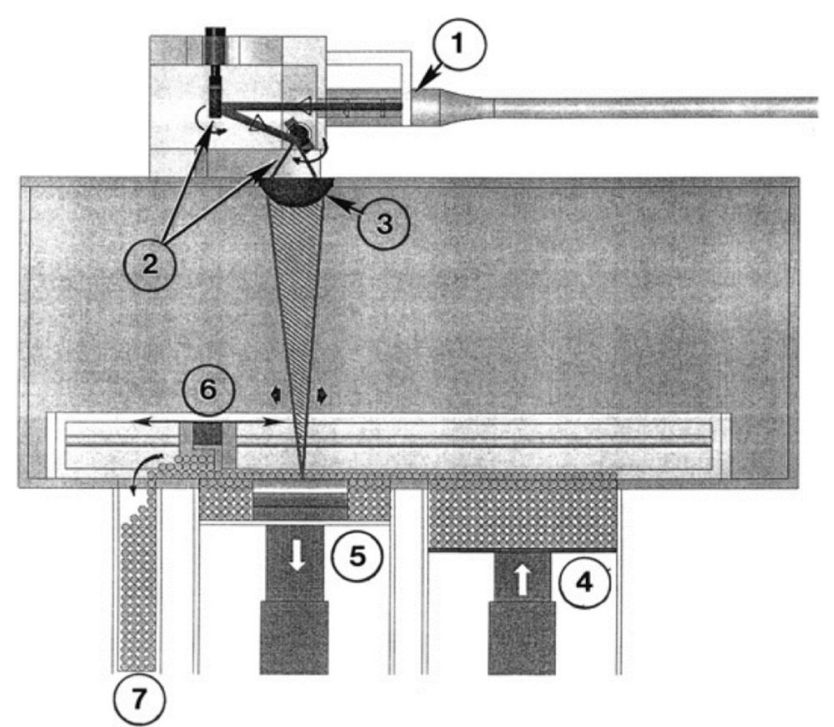

Fig. 4 SLM working system adapted from Ref. [81] ((1) laser; (2) mirror rotating system; (3) beam focus lens; (4) powder feeder system; (5) building platform; (6) powder recoater; (7) recycling system) but was inferior in elasticity due to the oxidation of the powders. In recent years, however, SLM is found to be enormously potential for fabricating prostheses with porous structures.

The mechanisms of pores formation during SLM was proposed by Wang et al. [106]. It was interesting to note that the laser scanning speed had a considerable influence on the resulted microstructure. A threshold speed value was found during processing, under which the product's porosity increased with the growing speed, but then decreased with the further increment of the scanning velocity. In their study, a highly porous titanium scaffold with $70 \%$ porosity and $200-500 \mu \mathrm{m}$ in pore size was achieved through carefully adjusting SLM processing conditions. The results are encouraging for the development of patient-specific implants. For more examples, Pattanayak et al. [111] successfully fabricated Ti metals with structures analogous to the human cancellous bone through optimizing SLM parameters such as laser power, hatching pattern and scanning speed. A lately study conducted by Weißmann et al. [112] confirmed the feasibility of fabricating lattice structures in Ti-6Al-4V with high geometrical accuracy using SLM [112]. Again, their works 
Table 2 Major advantages and disadvantages of SLM [103]

\begin{tabular}{|c|c|c|}
\hline Full melting & Benefits & Drawbacks \\
\hline $\begin{array}{r}\text { Material } \\
\text { choice }\end{array}$ & $\begin{array}{l}\text { No distinct binder and melt phases; hence, the process can produce } \\
\text { "single material" parts (e.g., steel, Ti or Al alloys), rather than } \\
\text { producing a composite green part which might not be desired }\end{array}$ & $\begin{array}{l}\text { Not suited for well controlled composite materials (e.g., } \\
\text { WC-Co) }\end{array}$ \\
\hline $\begin{array}{l}\text { Production } \\
\text { steps (time, } \\
\text { cost) }\end{array}$ & $\begin{array}{l}\text { Elimination of time consuming and costly furnace post-processes for } \\
\text { debinding (in case of polymer binder phase), infiltration or post- } \\
\text { sintering }\end{array}$ & $\begin{array}{l}\text { The laser powder processing needs higher energy level: } \\
\text { i.e., high laser power, good beam quality (more } \\
\text { expensive laser) and smaller scan velocities (longer } \\
\text { build times) }\end{array}$ \\
\hline Part quality & $\begin{array}{l}\text { Better suited to produce full dense parts (even over } 99.9 \% \text { ) in a direct } \\
\text { way, without post infiltration, sintering or HIPing }\end{array}$ & $\begin{array}{l}\text { SLM suffers more from melt pool instabilities (low } \\
\text { quality of down facing surfaces, higher upper surface } \\
\text { roughness, risk of internal pores) and higher residual } \\
\text { stresses (common need to build and anchor part on } \\
\text { solid base plate, risk of delamination, distortion when } \\
\text { removing base plate) }\end{array}$ \\
\hline
\end{tabular}

proved that SLM was a great useful technique for manufacturing customized bioimplants with complicated internal structures.

Many recent SLM studies showed the potential of fabricating advanced composite parts by adding functional material to metallic powders [103, 105]. Hao et al. [105] explored the feasibility of SLM processing stainless steel and HA powder mixture to produce bioactive implants for load-bearing application. Through judiciously selecting processing parameters, a composite artificial bone with an adequate tensile strength of $95 \mathrm{MPa}$ was fabricated. Their study confirmed that the existence of HA particles contributed to a finer grain size of stainless steel, hence enhanced the hardness of the finished products. The achieved mechanical properties would effectively protect surrounding bones from stress shielding after implantation. Except for metallic powders, SLM is also reported to be capable of manufacturing bioceramics. The additive manufacturing of zirconia-alumina ceramic components by SLM was investigated by Wilkes et al. [109]. In their study, the mixture of two ceramic powders realized a fine-grained eutectic microstructure and a completely melting helped to produce almost $100 \%$ density specimens. Internal cracks could be prevented by preheating the material. In this way, high flexural strength products could be fabricated for allceramic dental restorations. Such composite biomaterials are considered to be highly potent in future implant applications.

A comparison between above two AM processes is summarized in Table 3 [113]. Same as EBM, SLM process is effective in reducing the waste material since the unused powder can be recycled. Both techniques are able to achieve desired mechanical properties via controlling the product porosity. Although SLM has some advantages over EBM in terms of better feature resolution and surface finish, its long manufacturing time and excessive cost should be taken into consideration.

\section{Surface finishing processes}

After the completion of the pre-fabrication process, the near-net-shape bioimplant parts are manufactured by consecutive finishing steps. Generally, the milled conventional orthopaedics joints are subjected to a serious of grinding processes by machines with three or more axes [114]. Polishing is employed as the last step to achieve desired smooth surfaces, where the manual process is often involved [115, 116]. Due to the low fracture toughness, metallic and ceramic-based bioimplants are prone to brittle fractures during the abrasive machining. Therefore, precise grinding and polishing processes must be applied to ensure the material removal mode maintains in the ductile region. It is reported that there are about 60 individual machining steps required for even the relatively simple geometry of a ceramic hip replacement [114]. In contrast to hip implant components, the artificial knee joint has more complex and partly freeform surfaces, which raises the difficulty of manufacturing. In this case, the knowledge of machining simple geometric components cannot be uncritically conferred. Frequently changing contact conditions in the grinding process should be taken into consideration in order to ensure a constant material removal and high surface quality [117].

To increase working efficiency and reduce costs, various automated process chains for the manufacturing of bioimplants were designed. One typical example is presented by Turger et al. [114]. In their work, means of calculation and modelling works were applied to predict the surface quality after pre-grinding. The roughness peaks were levelled by subsequent polishing steps. Their work revealed that a 
Table 3 Comparision between EBM and SLM [113]

\begin{tabular}{|c|c|c|}
\hline & EBM & SLM \\
\hline Thermal source & Electron beam & Laser \\
\hline Atmosphere & Vacuum & Inert gas \\
\hline Scanning & Deflection coils & Galvanometers \\
\hline Energy absorption & Conductivity-limited & Absorptivity-limited \\
\hline Powder preheating & Use electron beam & Use infrared heaters \\
\hline Scan speed & Very fast, magnetically driven & Limited by galvanometer inertia \\
\hline Energy costs & Moderate & High \\
\hline Surface finish & Moderate to poor & Excellent to moderate \\
\hline Feature resolution & Moderate & Excellent \\
\hline Materials & Metals (conductors) & Metals, ceramics and polymers \\
\hline
\end{tabular}

reasonable procedure would contribute to the increment of productivity. It was estimated that polishing processes typically accounted for $10 \%-15 \%$ of the total manufacturing cost [118]. Aimed at reducing the probability of occurrence of the shape deviations and the necessary efforts in the following polishing process, innovative grinding technologies and highly precise processes have been developed.

\subsection{Precision grinding}

Conventional grinding of hard-brittle materials is featured as low grinding ratio accompanied with significant wheel wearing. Additionally, the grinding debris tends to block the wheel while grinding. Obviously, the uniformity of the abrasive grain distribution on the grinding wheel would be gradually influenced by the wear or inserted debris. A rise in the grinding forces would thus be involved and likely to trigger the brittle damages. Consequently, the grinding precision cannot be guaranteed. Such limitations are critical in manufacturing bioimplants as some certain specific parts of the orthopaedic joints have stringent surface requirements. To address above issues, electrolytic inprocess dressing (ELID) grinding was proposed. Figures 5 and 6 show the diameter and basic working principles and mechanisms of ELID grinding [119]. This technology offers an innovative approach to dress the metal-based grinding wheel by applying an electrolysis method. Sharp abrasives are revealed on anode while the metal-based bonding material and residuals inside the wheel are removed via electrolyzation.

Previous studies have illustrated that ELID grinding is an effective method to produce smooth surfaces with nanometric roughness on hard-brittle materials [120]. Plus, abrasives may be diffused into the workpiece surface during the grinding process, which is expected to promote the corrosion resistance of the finished products. As a

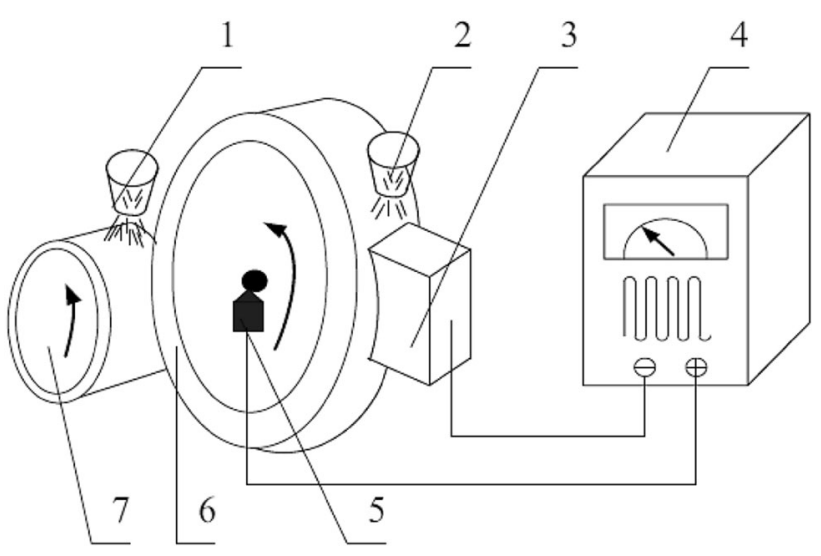

Fig. 5 Diagram of electrolytic in-process dressing ( 1 cooling liquid; 2 electrolyte; 3 electrode; 4 power supply; 5 brush power; 6 wheel; 7 workpiece) [119]

result, recent researches have indicated the unique suitability of ELID grinding on fabricating metallic or ceramic based bioimplants. Kotani et al. [121] applied this technique to machine Co-Cr-Mo alloys. Mirror surfaces that compared favourably with polished ones were achieved. Increasing the electrolytic current involved in the machining process was found to be helpful in improving the products' corrosion resistance, which was attributed to an oxide layer formed on the surface. However, a risk of inducing abrasive grain peeling that may worsen the surface finish should be considered. The group carried out a further study of proposing a new ELID grinding system to machine the inside surface of a hemispherical cup, as shown in Fig. 7 [122]. The hybrid process combining ELID grinding exhibited to be suitable for the surface finishing process for the sliding parts of metal-on-metal artificial hip joints. All the ground workpieces showed an improved surface roughness.

Toric grinding pins are favoured for the capabilities of handling very complex geometries. The bond geometry and 

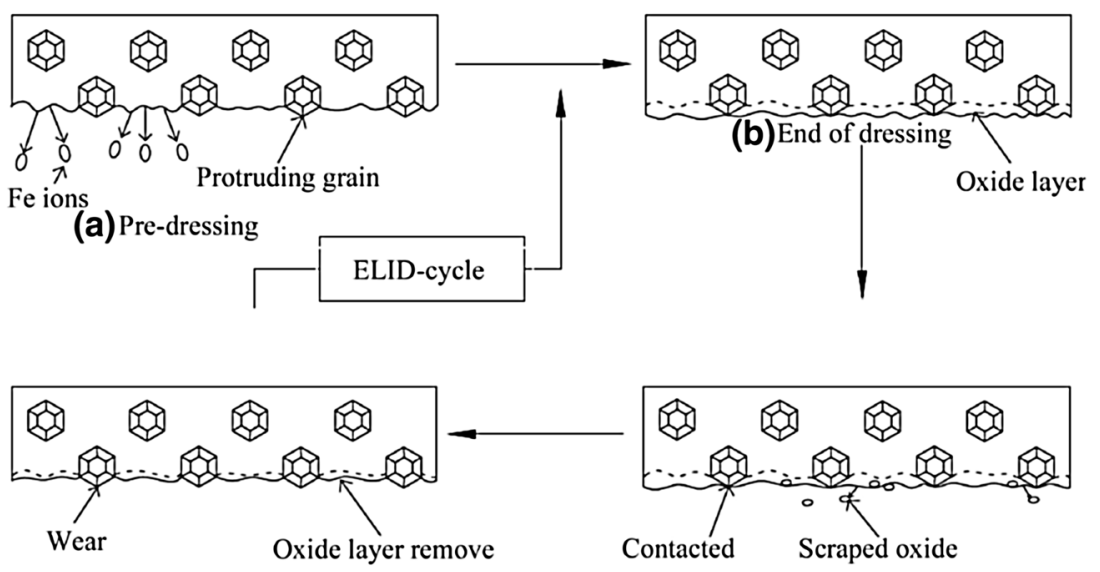

(d) Stabilization of ELID

(c) Start of ELID

Fig. 6 Working principles and mechanisms of ELID grinding [119]

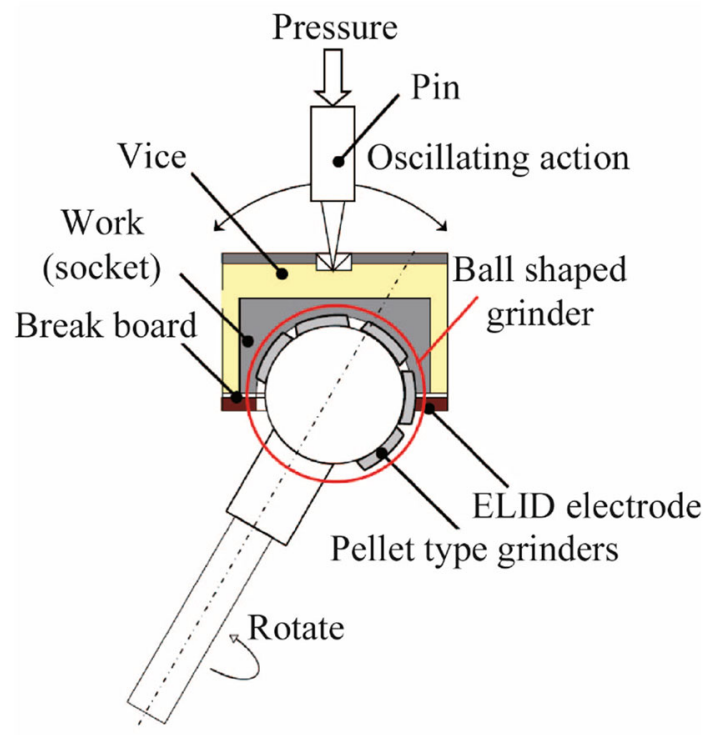

Fig. 7 Schematic illustration of the new ELID grinding system for machining hemispherical inside surface [122]

adjustable orientation towards the workpiece allow such machining method to adapt to various complicated shapes. For instance, big convex radii can be machined with an orthogonal orientation towards the workpiece. When a defined contact angle of the toric tool is used, small concave radii can be produced. This feature is significantly valuable for machining knee joints, because such bioimplants at least have two different radii of curvature. The issue of frequently changing contact conditions can be solved by precisely adjusting the tool position and varying the contact angle. Denkena et al. [117] described the contact conditions in a frontal grinding of workpieces analogical to knee joints with toric grinding pins. In their work, new calculation models were developed to predict the process characteristics such as geometric contact length/width, engagement zone and the material removal rate. The researchers confirmed a good approximation to the machined topography with minimum deviation. A prediction model for the theoretic kinematic roughness was also proposed later on. The validity of the prediction approach was further verified by means of grinding tests. Such achievements are believed to be beneficial for assuring a high-quality level of the manufacturing process.

\subsection{Polishing}

Polishing processes are generally used to create surfaces with a high grade of surface finishes. In many cases, grinding alone cannot meet the surface requirements for a variety of bioimplants. Machining bioimplants by means of grinding processes followed by polishing is a favourable solution for removing the remained damages. Figure 8 shows the surface quality with and without a finishing process of polishing [123]. It was reported that a smoother surface exhibited a better corrosion resistance, and hence prolonged the lifetime of the implant. In addition, the conformity between the coupling joints would reduce the friction coefficient, which was very attractive with respect to the bearing orthopaedic implants [123, 124]. Conventional polishing methods include free abrasive polishing, fixed abrasive polishing, belt polishing, etc., which have all been comprehensively investigated in the past decades. Nowadays, the polishing of bioimplants is normally integrated with high-precision CNC process to increase the working efficiency and to ensure a uniform material removal over the whole complex surfaces. With the development of sophisticated polishing machines, the roughness of polished spherical cups and balls have reached nanoscale [125]. In pursuit of a higher level of surface finish, researchers dedicated to the study of ultraprecision polishing. Cheung et al. [123] investigated the 

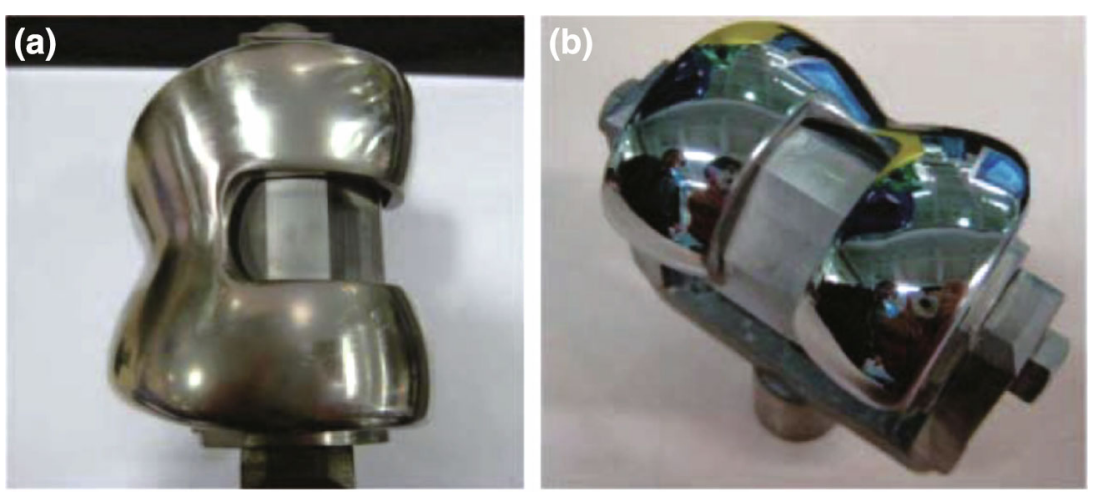

Fig. 8 Surface quality of an artificial knee implant a without and b with polishing [123]

factors that might affect the nanosurface generation in ultraprecision polishing. The study offered suitable strategies for optimizing the surface finish of freeform products. Improved surface quality was obtained with reduced expenses and working time. A set of optimum polishing conditions for machining Ti-based knee implants were then presented and experimentally verified. Superfinished orthopaedic implants with the surface roughness of below $10 \mathrm{~nm}$ were achieved.

Apart from purely mechanical polishing, chemical-mechanical polishing (CMP) technique was proved to be an alternative approach to generate optimal nano/microscale roughness on the metallic bioimplants [126, 127]. In CMP process, submicron size abrasives along with corrosives were mixed as polishing slurry. The top surface of the objective was firstly altered by the chemicals and removed by the mechanical action of abrasives afterwards [127]. A protective oxide layer would be generated on the CMP treated surfaces, whose thickness could be controlled within a certain extent. The application of CMP in bioimplants manufacturing showed advantages in limiting bacteria growth, promoting biocompatibilities and controlling cell attachment [127].

Since the conventional polishing processes are relatively more labour and time-consuming, along with introducing residual stresses to the surface layer, the electrochemical polishing (EP) is currently more recommended for the manufacturing of biological prostheses [124]. In the electrochemical polishing process, the anodic dissolution of metallic objectives occurs in an electrolyte [128]. The unevenness of surfaces is eliminated by anodic levelling that is based on the differences in dissolution rate. Such operating principle allows it to handle very complex workpiece geometries. The capability of improving surface performances has made EP greatly attractive for surface finishing of implant materials $[129,130]$. Currently, EP is most commonly performed on stainless steels [131, 132]. The improved biocompatibility and hemocompatibility of EP treated $316 \mathrm{~L}$ stainless steel was confirmed by
Habibzadeh et al. [133]. A significant growth in the attachment of endothelial cells and smooth muscle cells were observed. EP is also recognized as a promising technique to promote corrosion and wear resistance of bioimplants. Zaborski et al. [124] utilized electrochemical polishing as the finishing process for hip joint machining. The coarseness values obtained from the electrochemical polished heads of hip joint prostheses made of $316 \mathrm{~L}$ stainless steel and Ti-6Al-4V were between $0.05 \mu \mathrm{m}$ and $0.15 \mu \mathrm{m}$. Comparing to traditionally ground surfaces, the further smoothened surfaces increased the participation of the carrier surface by $25 \%-30 \%$, which would positively affect the wear intensity of matching surfaces. Moreover, it was found that the EP generated passive oxide layers on stainless steels were thicker than those naturally-grown passive films. As a result, a notable enhancement in corrosion resistance and pitting potential were offered in EP processed products [133].

Magnetorheological fluid-based finishing (MRFF) tool was developed for finishing complex freeform surfaces [134]. According to the literature, nanoscale level surface roughness could be achieved in complex freeforms through MRFF [116]. Recently, it shows a lot of potential in finishing knee joint implants owing to its flexibility [116, 135]. Sidpara and Jain [116] recommended MRFF to finish the surface of a prosthesis knee joint implant made of titanium. It was also suggested that the addition of appropriate chemicals would be conductive to improve the finishing rate of titanium, regardless of the high initial surface roughness. CNC machine could also be applied to shorten the working time. Figure 9 shows the schematic of MRFF tool and the finishing process of a knee joint using this process. Note that the process may not be suitable when the initial surface roughness is higher than $300 \mathrm{~nm}$ [116]. 


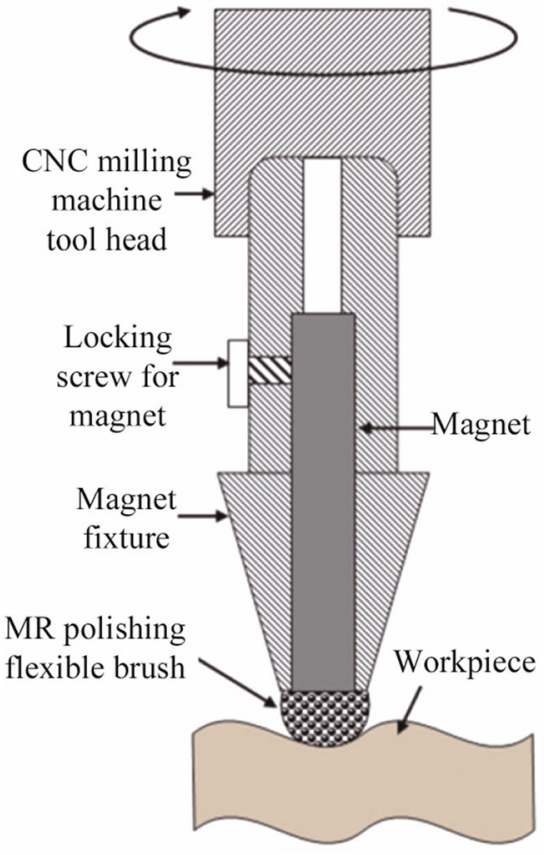

(a)

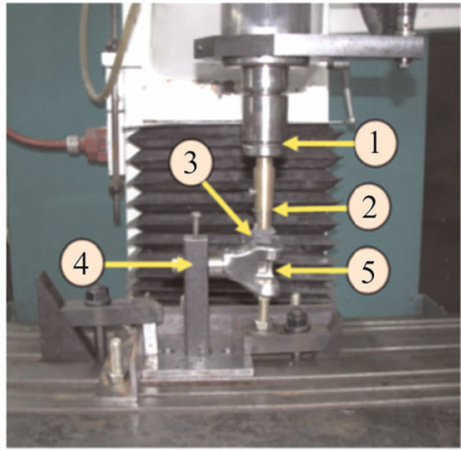

(b)

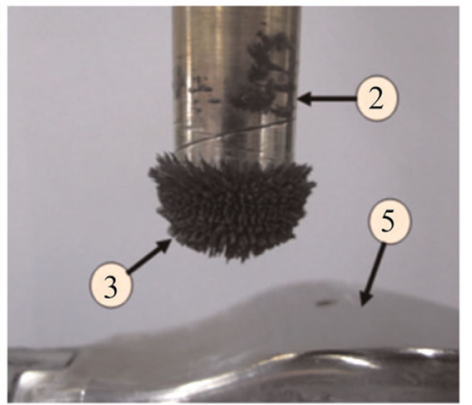

(c)

Fig. 9 a Schematic of the MRFF tool, b photograph of MR finishing tool for freeform surfacesand $\mathbf{c}$ close-up view of the MR polishing fluid (1 CNC milling machine head; 2 MR finishing tool; 3 MR polishing flexible brush; 4 fixture for knee joint implant; 5 knee joint implant) [116]

\section{Precision measurement}

Characterization and evaluation of bioimplant components are necessary for predicting the future performances or providing the information of failure causation. In the aim of selecting the most appropriate approach that realizes reliable and fast evaluations, principles of various techniques should be reviewed. Emphases are put on the geometry measurement.

It is widely accepted that profile errors are inevitable in the process of manufacturing. The factors that may induce profile error are various, such as machine structure error, environmental change, vibration and tool wear, etc. [134]. In order to ensure the desired product specifications in shape, size and surface topography are achieved, geometry metrology is a vital process in the manufacturing chain. As there is a growing tendency towards the miniaturization of products to produce sophisticated devices with novel properties, the accuracy of the measurement has been put forward a higher request.

With respect to the manufacturing of bioimplants, the metrology of biomedical surfaces plays an important role in optimizing the functional characteristics such as osseointegration, coating adhesion, lubricant retention, wear resistance, etc. In particular, the success of a joint orthopaedic replacement is highly related to the product accuracy with which the patient-prosthes is mismatch can be avoided. With an overall goal of increasing the bioimplants' lifetime and achieving biological conformance after implantation, both contact and non-contact measuring techniques are required to be applied to the finished products. In the following sections, some major geometrical measurement techniques for bioimplants will be presented.

\subsection{Conventional 2D imaging}

Visual inspection using an optical microscopy is the simplest way to characterize the surface structures. This method is not only fast but also flexible in different working conditions that work with varieties of workpieces. The theoretical highest resolution of a typical optical microscope is bound to the light wavelength, which is about half the wavelength value. With the recent development of novel optical microscopic techniques, nanoscaled resolution can be obtained with the singlewavelength light and high dynamic range function. Nevertheless, the resolution and depth of focus remain limited. Although more and more optical microscopy models are able to provide a three-dimensional view of the workpiece surface with a built-in graphic processing software, the 
detailed surface roughness and topography cannot be accurately described.

Scanning electron microscopy (SEM) has much higher magnification and resolution than optical microscopes. During the measurement, the workpiece surface is scanned with an electron beam in a vacuum environment. The signals of reflected secondary electrons and electromagnetic waves are collected so the surface geometries can be obtained. The emitted backscatter electrons are affected by the atom mass, so they are used to investigate the surface homogeneity or identify a certain element. Due to this technique that can be applied in combination with biological assays, it has been extensively used in biomanufacturing for qualitative observation of biofilm disruption, bone formation and degradable bioimplant dissolution process [136, 137]. Nowadays, typical SEM is capable of providing sub-nanometric resolution in both horizontal and vertical directions. However, like optical microscopic techniques, the analysis of surface roughness is limited as only two-dimensional images can be provided.

\subsection{Coordinate measuring machines}

Coordinate measuring machines (CMM) are at president the most commonly utilized instruments for measuring free-form parts in contact mode [134]. In a CMM system, the measurements are defined by a probe attached to the machine whose 2D/3D displacements are detected with high resolution and low contact forces. The probe is the most important part for CMM. Conventional probes are mechanical, while today they are normally combined with laser, optical or white light for multisensory measurement [138]. Currently, there are varieties of probing systems that are commercially available to perform different kinds of measurement tasks. Many researchers and manufacturers are also devoted to developing their own CMM probing systems. The large numbers of probes that can be employed are described in Ref. [134]. Basically, there are four sequential tasks that are involved in a CMM measurement process, i.e., positioning, probing, measuring and evaluating. The factors that may affect the probe performances were summarized by Weckenmann et al. [138], as shown in Fig. 10.

As a contacting technique, CMM is particularly advantageous in measuring steep-sided features due to the large dynamic range [34]. In addition, the resolution of vertical height measurement allows the direct extraction of texture information, which is helpful in evaluating the performances of hip joints and dental implants [34, 139]. However, CMM system is deficient with regard to microscale measurement. Efforts have been made on improving the precision of CMM by applying microprobes [140], where the diameter of the probe tip is carefully selected from a few micrometres to hundreds of micrometres according to the specifications of the measurement objectives. Employing laser interferometers or optimizing machine design would also be effective in measuring microstructures [141]. In terms of the measurement speed, it can be increased via multi-point probing or optical probing with high data rate [34, 142]. After measurement, compensated probing results should be involved to guarantee robust results. Apart from above, adding extra functions for measuring nondimensional quantities such as hardness, magnetic and electric properties in the same system would be conducive to saving time and money.

\subsection{Scanning probe microscopy}

Scanning probe microscopy (SPM) is a favoured technique in observing atomic surface structures within an extremely narrow region [143]. Typical representatives of SPM include atomic force microscopy (AFM) and scanning tunnelling microscopy (STM). The achievement of scanning in AFM is based on a sharp cantilever tip with small curvature, while STM utilizes an electrical near-field interaction with a conductive surface [134]. The contact mode of AFM is the most commonly used technique to produce 3D surface images [144]. It shares the similar working principle as CMM system [134], where the cantilever tip is in touch with the workpiece during measuring. However, due to the interaction forces between the tip and sample, damages may be formed on soft surfaces and hence create distorted images. To address this issue, the noncontact mode was developed, in which the cantilever vibrates above the workpiece and senses the attractive Van der Waals forces in between [144]. Although CMM and optical methods are preferred in the case of fast and largearea inspection, SPM plays an irreplaceable role in highresolution imaging with quantitative results. It is reported that SPM techniques are capable of offering a sub-nanometric resolution in the vertical direction and laterally in the nanometre range. Besides, the high vacuum and conductive coatings required for SEM is no longer compulsory in SPM. What makes SPM appealing for biomanufacturing is that non-contact mode permits the measurement of live biological specimens with sensitive surfaces in the presence of hydration or fluid [34, 143]. Moreover, AFM can be used to yield data on the viscoelasticity of biomolecular layers on biomaterials [145].

The limitations of SPM are obvious. Typically, the advantage of achieving high resolution has to be balanced against the restricted working range. Measurements can only be conducted on specific areas on a surface. Thus, attempts have been made on integrating SPM with CMM to increase the lateral working range to tens of micrometres [134]. The long scanning period is another disadvantage of 


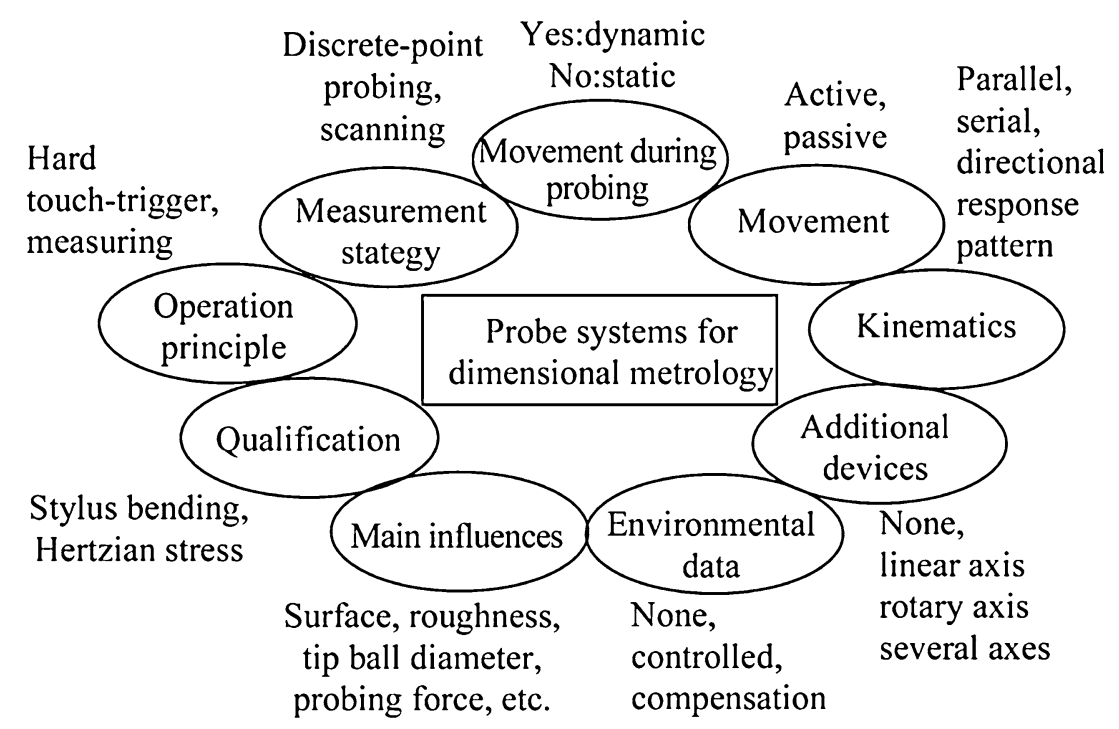

Fig. 10 Aspects of probing systems [138]

SPM. To reduce the measurement time, a feature-oriented measurement strategy is implemented. High-resolution scanning would be selectively performed on certain areas and hence enable the optimization of the measuring operation [146].

\subsection{Optical profiler}

Instead of having a mechanical probe touching the sample surface, optical profiler uses a light beam to scan the workpiece. Like non-contact SPM methods, the significant merit of optical profiling is that the physical damages and chemical changes can be avoided. There are two main categories of optical profilometers: focus detection profilometers and interferometric profilometers [144]. The focus detection profilometer, also called as laser profilometer, maintains the projected beam in focus on the workpiece surface by vertically moving the lens. The vertical movement of the lens thus reflects the height variation of the workpiece. The resolution of laser profilometer is tied to the size of the beam. Generally, laser profilometer is capable of offering a good overview of the surface roughness within a reasonable measuring time [144]. The interferometric profilometer, as can be told from the name, is based on the interference phenomenon. During the measurement, an interference pattern between the measuring beam and reference beam is formed to accurately derive the information of height difference. This technique is popular in the fast measuring of surfaces with sub-nanometric features in the direction of beam propagation [134, 147]. Quick repeatable measurements and a good representation of the surface texture can be realized. In addition, the optical imaging function is attractive for live biological samplesas it is well-suited for recording the changing roughness [148, 149].

However, the results obtained from optical profiler are not directly comparable to those gained from contact mode measurements. This is a particularly critical disadvantage in measuring biological surfaces [34]. Furthermore, steep slopes can be hardly measured using optical techniques as out of focus is easy to occur. The attempts of regaining the focus made by the optical system would eventually lead to erroneous data.

\section{Conclusions and perspective}

Manufacturing of bioimplants involves both mechanical and biological engineering, and usually requires integrating multiple processes of material selection, forming processing, surface finishing and evaluation of finished products. Hence the structure of this review is organized according to the topics above. For the material selection, although imperfect, metallic biomaterials of stainless steel, cobaltand titanium-alloys remain the mainstream in orthopaedic implantation. Considering that the service longevity of most metallic bioimplants is limited to around 20 years and the incident failures are likely to occur after 15 years' service, major attempts have been leaning to investigate the feasibilities of polymers, ceramics and other composite biomaterials in orthopaedics. Developing the new generation of biomaterial brings knowledge together from a variety of disciplines, which is a spotlight topic in the future study of biomedical engineering.

The major issue encountered for most load-bearing orthopaedic devices is the stress-shielding effect, which could be solved via altering the elastic modulus of 
bioimplant close to bones. In this regard, introducing porosity structures to the body which is receiving an implant is believed to be the most promising strategy, although the compromises in fatigue resistance are inevitable. The porosity of implant should be able to be tailored at the fabrication stage to mechanically match with the surrounding tissues, as well as to encourage host bones to grow into it. Therefore, fabrication technologies such as powder metallurgy process, electron beam melting, selective laser melting, etc., show enormous promises. Another idea that may enable better integration between the bioimplants and host body is based on the advancing of fabrication. Manufacturing commercial customized bioimplants show great development potential in offering particular constructs for specific defect or injury. With the significant demand from the society and industry, proposing highly efficient and cost-effective fabrication approaches with reduced follow-up processes should be the first priority. Surface finishing of the bioimplants is as equally important as the forming processes. Nano-manufacturing is an emerging research area for the manufacturing of highquality and high-precision bioimplants, with the form precision reaching sub-microns and surface roughness in nanometre range.

For successful applications, the quality and performance of implant products must be thoroughly evaluated. Typical metrology processes based on both contact and non-contact modes have been proposed for biomedical surfaces. The ideal advantages of innovative topographic metrology include high flexibility while achieving high resolution within a short time. On-machine measurement can be used for sophisticated parts of an implant during the fabrication process. This is to avoid geometrical errors induced in the matching process later on. There is also a need to develop performance-related evaluation process for the comprehensive evaluation of bioimplants with high efficiency.

Acknowledgements Acknowledgements are extended to the support received from the Science Foundation Ireland (SFI) (Grant No. 15/RP/B3208) and the National Science Foundation of China (Grant Nos. 51320105009 \& 61635008).

Open Access This article is distributed under the terms of the Creative Commons Attribution 4.0 International License (http://crea tivecommons.org/licenses/by/4.0/), which permits unrestricted use, distribution, and reproduction in any medium, provided you give appropriate credit to the original author(s) and the source, provide a link to the Creative Commons license, and indicate if changes were made.

\section{References}

1. Manivasagam G, Dhinasekaran D, Rajamanickam A (2010) Biomedical implants: corrosion and its prevention-a review. Recent Pat Corros Sci 2(1):40-54
2. Luthringer B, Feyerabend F, Willumeit-Römer R (2014) Magnesium-based implants: a mini-review. Magnes Res 27(4):142-154

3. Geetha M, Singh A, Asokamani R et al (2009) Ti based biomaterials, the ultimate choice for orthopaedic implants-a review. Prog Mater Sci 54(3):397-425

4. Walczak J, Shahgaldi F, Heatley F (1998) In vivo corrosion of 316L stainless-steel hip implants: morphology and elemental compositions of corrosion products. Biomaterials 19(1-3):229-237

5. Case C, Langkamer V, James C et al (1994) Widespread dissemination of metal debris from implants. Bone Joint $\mathrm{J}$ 76(5):701-712

6. Prikryl M, Srivastava S, Viviani G et al (1989) Role of corrosion in harrington and luque rods failure. Biomaterials 10(2):109-117

7. Sumita M, Hanawa T, Ohnishi I et al (2003) Failure processes in biometallic materials. In: Milne I, Ritchie R, Karihaloo BL (eds) IMOR Karihaloo, comprehensive structural integrity, Pergamon, Oxford, pp 131-167

8. Davis JR (2003) Handbook of materials for medical devices. ASM International, Metals Park

9. Shetty RH, Ottersberg WH (1995) Metals in orthopedic surgery. Encycl Handb Biomater Bioeng 1:509-540

10. Lemons J, Niemann K, Weiss A (1976) Biocompatibility studies on surgical-grade titanium-, cobalt-, and iron-base alloys. J Biomed Mater Res, Part A 10(4):549-553

11. Escalas F, Galante J, Rostoker W et al (1976) Biocompatibility of materials for total joint replacement. J Biomed Mater Res, Part A 10(2):175-195

12. Syrett BC, Davis EE (1979) In vivo evaluation of a highstrength, high-ductility stainless steel for use in surgical implants. J Biomed Mater Res, Part A 13(4):543-556

13. Breme H, Biehl V, Helsen J (1998) Metals and implants. Metals Biomater 615(46):37-72

14. David Y (1999) The biomedical engineering handbook. In: Bronzino JD (ed) The biomedical engineering handbook, 2nd edn. 2 Volume Set. CRC Press, Boca Raton

15. Wiles P (1958) The surgery of the osteo-arthritic hip. Br J Surg 45(193):488-497

16. Wiles P (2003) The classic: the surgery of the osteo-arthritic hip. Clin Orthop Relat Res 417:3-16

17. Niinomi M, Nakai M, Hieda J (2012) Development of new metallic alloys for biomedical applications. Acta Biomater 8(11):3888-3903

18. Chen Q, Thouas GA (2015) Metallic implant biomaterials. Mater Sci Eng R Rep 87:1-57

19. Taira M, Lautenschlager EP (1992) In vitro corrosion fatigue of 316L cold worked stainless steel. J Biomed Mater Res 26(9):1131-1139

20. Weldon L, McHugh P, Carroll W et al (2005) The influence of passivation and electropolishing on the performance of medical grade stainless steels in static and fatigue loading. J Mater Sci Mater Med 16(2):107-117

21. Roland T, Retraint D, Lu K et al (2006) Fatigue life improvement through surface nanostructuring of stainless steel by means of surface mechanical attrition treatment. Scr Mater 54(11):1949-1954

22. Sudarshan T, Srivatsan T, Harvey D (1990) Fatigue processes in metals-role of aqueous environments. Eng Fract Mech 36(6):827-852

23. Ebara R (2010) Corrosion fatigue crack initiation behavior of stainless steels. Procedia Eng 2(1):1297-1306

24. Vahey J, Simonian P, Conrad E (1995) Carcinogenicity and metallic implants. Am J Orthoped (Belle Mead, NJ) 24(4):319-324 
25. Lei M, Zhu X (2001) In vitro corrosion resistance of plasma source ion nitrided austenitic stainless steels. Biomaterials 22(7):641-647

26. Nail-plates F (1959) Corrosion of orthopaedic implants. J Bone Jt Surg B 41:810-820

27. Muley SV, Vidvans AN, Chaudhari GP et al (2016) An assessment of ultra fine grained $316 \mathrm{~L}$ stainless steel for implant applications. Acta Biomater 30:408-419

28. Pramanik S, Agarwal AK, Rai K (2005) Chronology of total hip joint replacement and materials development. Trends Biomater Artif Organs 19(1):15-26

29. Patel NR, Gohil PP (2012) A review on biomaterials: scope, applications \& human anatomy significance. Int $\mathrm{J}$ Emerg Technol Adv Eng 2(4):91-101

30. Alvarado J, Maldonado R, Marxuach J et al (2003) Biomechanics of hip and knee prostheses. Appl Eng Mech Med GEDUniversity of Puerto Rico Mayaguez

31. Evans E, Thomas I (1986) The in vitro toxicity of cobaltchrome-molybdenum alloy and its constituent metals. Biomaterials 7(1):25-29

32. Öztürk O, Türkan Uu, Eroğlu AE (2006) Metal ion release from nitrogen ion implanted CoCrMo orthopedic implant material. Surf Coat Technol 200(20):5687-5697

33. Vidal CV, Muñoz AI (2009) Effect of thermal treatment and applied potential on the electrochemical behaviour of CoCrMo biomedical alloy. Electrochim Acta 54(6):1798-1809

34. Ramsden JJ, Allen DM, Stephenson DJ et al (2007) The design and manufacture of biomedical surfaces. CIRP Ann Manuf Technol 56(2):687-711

35. Rudolf E (1998) A review of findings on chromium toxicity. Acta Med (Hradec Kralove) Suppl 41(1):55-65

36. Dayan A, Paine A (2001) Mechanisms of chromium toxicity, carcinogenicity and allergenicity: review of the literature from 1985 to 2000. Hum Exp Toxicol 20(9):439-451

37. Barceloux DG, Barceloux D (1999) Chromium. J Toxicol Clin Toxicol 37(2):173-194

38. Barceloux DG, Barceloux D (1999) Nickel. J Toxicol Clin Toxicol 37(2):239-258

39. Anke M, Seifert M, Arnhold W et al (2010) The biological and toxicological importance of molybdenum in the environment and in the nutrition of plants, animals and man: part V: essentiality and toxicity of molybdenum. Acta Aliment 39(1):12-26

40. Nagels J, Stokdijk M, Rozing PM (2003) Stress shielding and bone resorption in shoulder arthroplasty. J Shoulder Elbow Surg 12(1):35-39

41. Park JB, Lakes RS (2007) Hard tissue replacement II: joints and teeth. In: Hasirci N, Hasirci V (eds) Biomaterials. Springer, Boston, pp 317-354

42. Long M, Rack H (1998) Titanium alloys in total joint replacement-a materials science perspective. Biomaterials 19(18):1621-1639

43. Pais I, Feher M, Farkas E et al (1977) Titanium as a new trace element. Commun Soil Sci Plant Anal 8(5):407-410

44. Okazaki Y (2002) Effect of friction on anodic polarization properties of metallic biomaterials. Biomaterials 23(9):2071-2077

45. Yaghoubi S, Schwietert CW, McCue JP (2000) Biological roles of titanium. Biol Trace Elem Res 78(1-3):205

46. Niinomi M (2008) Biologically and mechanically biocompatible titanium alloys. Mater Trans 49(10):2170-2178

47. Niinomi M (2002) Recent metallic materials for biomedical applications. Metall Mater Trans A 33(3):477-486

48. Niinomi M (2003) Recent research and development in titanium alloys for biomedical applications and healthcare goods. Sci Technol Adv Mater 4(5):445-454
49. Niinomi M (1999) Recent titanium R\&D for biomedical applications in Japan. JOM 51(6):32-34

50. Charnley J (1970) Total hip replacement by low-friction arthroplasty. Clin Orthop Relat Res 72:7-21

51. Ramakrishna S, Mayer J, Wintermantel E et al (2001) Biomedical applications of polymer-composite materials: a review. Compos Sci Technol 61(9):1189-1224

52. Kurella A, Dahotre NB (2005) Review paper: surface modification for bioimplants: the role of laser surface engineering. J Biomater Appl 20(1):5-50

53. Hench LL, Wilson J (1993) An introduction to bioceramics, vol 1. World Scientific, Singapore

54. Katti KS (2004) Biomaterials in total joint replacement. Colloids Surf B 39(3):133-142

55. Kamitakahara M, Ohtsuki C, Miyazaki T (2008) Review paper: behavior of ceramic biomaterials derived from tricalcium phosphate in physiological condition. J Biomater Appl 23(3):197-212

56. Park JB, Bronzino JD (2002) Biomaterials: principles and applications. CRC Press, Boca Raton

57. De Aza P, De Aza A, Pena P et al (2007) Bioactive glasses and glass-ceramics. Bol Soc Esp Ceram Yvid 46(2):45

58. Hench LL (1991) Bioceramics: from concept to clinic. J Am Ceram Soc 74(7):1487-1510

59. Daculsi G (1998) Biphasic calcium phosphate concept applied to artificial bone, implant coating and injectable bone substitute. Biomaterials 19(16):1473-1478

60. Fujita Y, Yamamuro T, Nakamura T et al (1991) The bonding behavior of calcite to bone. J Biomed Mater Res, Part A 25(8):991-1003

61. Piconi C, Maccauro G (1999) Zirconia as a ceramic biomaterial. Biomaterials 20(1):1-25

62. Ikada Y (2002) Recent research developments in biomaterials. Research Signpost, India

63. Boutin P (1971) Alumina and its use in surgery of the hip. (Experimental study). La Presse Medicale 79(14):639-640

64. Kokubo T (2008) Bioceramics and their clinical applications. Laryngoscope 92(1):1103-1115

65. Heros RJ, Willmann G (1998) Ceramics in total hip arthroplasty: history, mechanical properties, clinicalresults, and current manufacturing state of the art. Semin Arthroplast 9:114-122

66. De Aza A, Chevalier J, Fantozzi G et al (2002) Crack growth resistance of alumina, zirconia and zirconia toughened alumina ceramics for joint prostheses. Biomaterials 23(3):937-945

67. Helmer J, Driskell T (1969) Research on bioceramics. In: Symposium on use of ceramics as surgical implants, South Carolina

68. Christel P, Meunier A, Dorlot JM et al (1988) Biomechanical compatibility and design of ceramic implants for orthopedic surgery. Ann NY Acad Sci 523(1):234-256

69. Chevalier J (2006) What future for zirconia as a biomaterial? Biomaterials 27(4):535-543

70. Hummer CD, Rothman RH, Hozack WJ (1995) Catastrophic failure of modular zirconia-ceramic femoral head components after total hip arthroplasty. J Arthroplasty 10(6):848-850

71. Best S, Porter A, Thian E et al (2008) Bioceramics: past, present and for the future. J Eur Ceram Soc 28(7):1319-1327

72. Fathi M, Hanifi A, Mortazavi V (2008) Preparation and bioactivity evaluation of bone-like hydroxyapatite nanopowder. J Mater Process Technol 202(1):536-542

73. LeGeros RZ (2002) Properties of osteoconductive biomaterials: calcium phosphates. Clin Orthop Relat Res 395:81-98

74. Ducheyne P, Cuckler JM (1992) Bioactive ceramic prosthetic coatings. Clin Orthop Relat Res 276:102-114 
75. Mohseni E, Zalnezhad E, Bushroa AR (2014) Comparative investigation on the adhesion of hydroxyapatite coating on Ti6Al-4V implant: a review paper. Int J Adhes Adhes 48:238-257

76. Hench LL, Splinter RJ, Allen W et al (1971) Bonding mechanisms at the interface of ceramic prosthetic materials. J Biomed Mater Res Part A 5(6):117-141

77. Jarcho M, Kay JF, Gumaer KI et al (1977) Tissue, cellular and subcellular events at a bone-ceramic hydroxylapatite interface. J Bioeng 1(2):79-92

78. Bartolo P, Kruth JP, Silva J et al (2012) Biomedical production of implants by additive electro-chemical and physical processes. CIRP Ann Manuf Technol 61(2):635-655

79. Poser R, Magee F, Kay J et al (1990) In-vivo characterization of a hydroxylapatite coating. In: Transactions of the 16th annual meeting of the society for biomaterials, 1990, p 170

80. Murr L, Amato K, Li S et al (2011) Microstructure and mechanical properties of open-cellular biomaterials prototypes for total knee replacement implants fabricated by electron beam melting. J Mech Behav Biomed Mater 4(7):1396-1411

81. Murr L, Quinones S, Gaytan S et al (2009) Microstructure and mechanical behavior of Ti-6Al-4V produced by rapid-layer manufacturing, for biomedical applications. J Mech Behav Biomed Mater 2(1):20-32

82. Lampman S (1990) Wrought titanium and titanium alloys. ASM Int Metals Handb Tenth Edn 2:592-633

83. Balagna C, Faga M, Spriano S (2012) Tantalum-based multilayer coating on cobalt alloys in total hip and knee replacement. Mater Sci Eng C 32(4):887-895

84. Jovanović M, Tadić S, Zec S et al (2006) The effect of annealing temperatures and cooling rates on microstructure and mechanical properties of investment cast Ti-6Al-4V alloy. Mater Des 27(3):192-199

85. Lin CW, Ju CP, Lin JH (2005) A comparison of the fatigue behavior of cast Ti-7.5 Mo with c.p. titanium, Ti-6Al-4V and Ti$13 \mathrm{Nb}-13 \mathrm{Zr}$ alloys. Biomaterials 26(16):2899-2907

86. Harrysson OL, Cansizoglu O, Marcellin-Little DJ et al (2008) Direct metal fabrication of titanium implants with tailored materials and mechanical properties using electron beam melting technology. Mater Sci Eng C 28(3):366-373

87. Eisen W, Ferguson B, German R et al (1998) Powder metal technologies and applications. In: Narayan R (ed) ASM handbook, vol 7. ASM International, USA, pp 308-2096

88. Davim JP (2008) Machining: fundamentals and recent advances. Springer, New York

89. Dewidar MM, Yoon HC, Lim JK (2006) Mechanical properties of metals for biomedical applications using powder metallurgy process: a review. Met Mater Int 12(3):193-206

90. Kuboki Y, Takita H, Kobayashi D et al (1998) BMP-induced osteogenesis on the surface of hydroxyapatite with geometrically feasible and nonfeasible structures: topology of osteogenesis. J Biomed Mater Res Part A 39(2):190-199

91. Vasconcellos LMRd, Oliveira MVd, Graça MLdA et al (2008) Porous titanium scaffolds produced by powder metallurgy for biomedical applications. Mater Res 11(3):275-280

92. Dewidar MM, Khalil KA, Lim J (2007) Processing and mechanical properties of porous $316 \mathrm{~L}$ stainless steel for biomedical applications. Trans Nonferr Metals Soc China 17(3):468-473

93. Seah K, Thampuran R, Teoh S (1998) The influence of pore morphology on corrosion. Corros Sci 40(4-5):547-556

94. Ryan G, Pandit A, Apatsidis DP (2006) Fabrication methods of porous metals for use in orthopaedic applications. Biomaterials 27(13):2651-2670

95. Ning C, Zhou Y (2002) In vitro bioactivity of a biocomposite fabricated from $\mathrm{HA}$ and $\mathrm{Ti}$ powders by powder metallurgy method. Biomaterials 23(14):2909-2915
96. Grądzka-Dahlke M, Dąbrowski J, Dąbrowski B (2008) Modification of mechanical properties of sintered implant materials on the base of Co-Cr-Mo alloy. J Mater Process Technol 204(1):199-205

97. Elahinia MH, Hashemi M, Tabesh M et al (2012) Manufacturing and processing of NiTi implants: a review. Prog Mater Sci 57(5):911-946

98. Gong X, Anderson T, Chou K (2012) Review on powder-based electron beam additive manufacturing technology. In: ASME/ ISCIE international symposium on flexible automation. American Society of Mechanical Engineers, pp 507-515

99. Frazier WE (2014) Metal additive manufacturing: a review. J Mater Eng Perform 23(6):1917-1928

100. Heinl P, Rottmair A, Körner C et al (2007) Cellular titanium by selective electron beam melting. Adv Eng Mater 9(5):360-364

101. Heinl P, Müller L, Körner C et al (2008) Cellular Ti-6Al-4V structures with interconnected macro porosity for bone implants fabricated by selective electron beam melting. Acta Biomater 4(5):1536-1544

102. Murr L, Gaytan S, Medina F et al (2010) Next-generation biomedical implants using additive manufacturing of complex, cellular and functional mesh arrays. Philos Trans R Soc Lond A Math Phys Eng Sci 368(1917):1999-2032

103. Kruth JP, Levy G, Klocke F et al (2007) Consolidation phenomena in laser and powder-bed based layered manufacturing. CIRP Ann Manuf Technol 56(2):730-759

104. Yadroitsev I, Bertrand P, Smurov I (2007) Parametric analysis of the selective laser melting process. Appl Surf Sci 253(19):8064-8069

105. Hao L, Dadbakhsh S, Seaman O et al (2009) Selective laser melting of a stainless steel and hydroxyapatite composite for load-bearing implant development. J Mater Process Technol 209(17):5793-5801

106. Wang Y, Shen Y, Wang Z et al (2010) Development of highly porous titanium scaffolds by selective laser melting. Mater Lett 64(6):674-676

107. Liverani E, Fortunato A, Leardini A et al (2016) Fabrication of $\mathrm{Co}-\mathrm{Cr}-\mathrm{Mo}$ endoprosthetic ankle devices by means of selective laser melting (SLM). Mater Des 106:60-68

108. Xin XZ, Chen J, Xiang N et al (2013) Surface properties and corrosion behavior of $\mathrm{Co}-\mathrm{Cr}$ alloy fabricated with selective laser melting technique. Cell Biochem Biophys 67(3):983-990

109. Wilkes J, Hagedorn YC, Meiners W et al (2013) Additive manufacturing of $\mathrm{ZrO}_{2}-\mathrm{Al}_{2} \mathrm{O}_{3}$ ceramic components by selective laser melting. Rapid Prototyp J 19(1):51-57

110. Zhang L, Klemm D, Eckert J et al (2011) Manufacture by selective laser melting and mechanical behavior of a biomedical Ti-24Nb-4Zr-8Sn alloy. Scr Mater 65(1):21-24

111. Pattanayak DK, Fukuda A, Matsushita T et al (2011) Bioactive Ti metal analogous to human cancellous bone: fabrication by selective laser melting and chemical treatments. Acta Biomater 7(3):1398-1406

112. Weißmann V, Bader R, Hansmann H et al (2016) Influence of the structural orientation on the mechanical properties of selective laser melted Ti6A14V open-porous scaffolds. Mater Des 95:188-197

113. Mueller B (2012) Additive manufacturing technologies: rapid prototyping to direct digital manufacturing. Assem Autom 32(2):151-154

114. Turger A, Köhler J, Denkena B et al (2013) Manufacturing conditioned roughness and wear of biomedical oxide ceramics for all-ceramic knee implants. Biomed Eng Online 12(1):84. https://doi.org/10.1186/1475-925X-12-84

115. Hilerio I, Mathia T, Alepee C (2004) 3D measurements of the knee prosthesis surfaces applied in optimizing of manufacturing process. Wear 257(12):1230-1234 
116. Sidpara AM, Jain V (2012) Nanofinishing of freeform surfaces of prosthetic knee joint implant. Proc Inst Mech Eng Part B J Eng Manuf 226(11):1833-1846

117. Denkena B, de Leon L, Turger A et al (2010) Prediction of contact conditions and theoretical roughness in manufacturing of complex implants by toric grinding tools. Int $\mathrm{J}$ Mach Tools Manuf 50(7):630-636

118. Jain V (2008) Abrasive-based nano-finishing techniques: an overview. Mach Sci Technol 12(3):257-294

119. Zhang D, Li C, Jia D et al (2014) Grinding model and material removal mechanism of medical nanometer zirconia ceramics. Recent Pat Nanotechnol 8(1):2-17

120. Ohmori H, Nakagawa $\mathrm{T}$ (1995) Analysis of mirror surface generation of hard and brittle materials by ELID (electronic inprocess dressing) grinding with superfine grain metallic bond wheels. CIRP Ann Manuf Technol 44(1):287-290

121. Kotani H, Komotori J, Mizutani M et al (2009) Surface finishing and modification for cobalt-chromium-molybdenum alloy by electrolytic in-process dressing (ELID) grinding. In: 5th international conference on leading edge manufacturing in $21 \mathrm{st}$ century, LEM 2009

122. Kotani H, Komotori J, Naruse T et al (2013) Development of a new grinding system for finishing of hemispherical inside surface. Int J Nanomanuf 9(1):77-86

123. Cheung C, Ho L, Charlton P et al (2010) Analysis of surface generation in the ultraprecision polishing of freeform surfaces. Pro Inst Mech Eng Part B J Eng Manuf 224(1):59-73

124. Zaborski S, Sudzik A, Wołyniec A (2011) Electrochemical polishing of total hip prostheses. Arch Civ Mech Eng 11(4):1053-1062

125. Zhang LC, Kiat E, Pramanik A(2009) A briefing on the manufacture of hip joint prostheses. In: 12th international symposium on advances in abrasive technology (ISAAT2009). Gold Coast, Australia, 2009, pp 212-216

126. Basim GB, Ozdemir Z (2015) Chemical mechanical polishing implementation on dental implants. In: International conference on planarization/CMP technology (ICPT). IEEE, pp 1-4

127. Ozdemir Z, Ozdemir A, Basim G (2016) Application of chemical mechanical polishing process on titanium based implants. Mater Sci Eng C 68:383-396

128. Landolt D (1987) Fundamental aspects of electropolishing. Electrochim Acta 32(1):1-11

129. Hryniewicz T, Rokicki R, Rokosz K (2008) Co-Cr alloy corrosion behaviour after electropolishing and "magnetoelectropolishing" treatments. Mater Lett 62(17):3073-3076

130. Hryniewicz T, Rokosz K, Rokicki R et al (2015) Nanoindentation and XPS studies of titanium TNZ alloy after electrochemical polishing in a magnetic field. Materials 8(1):205-215

131. Hryniewicz T, Rokicki R, Rokosz K (2008) Surface characterization of AISI 316L biomaterials obtained by electropolishing in a magnetic field. Surf Coat Technol 202(9):1668-1673

132. Magaino S, Matlosz M, Landolt D (1993) An impedance study of stainless steel electropolishing. J Electrochem Soc 140(5):1365-1373
133. Habibzadeh S, Li L, Shum-Tim D et al (2014) Electrochemical polishing as a $316 \mathrm{~L}$ stainless steel surface treatment method: towards the improvement of biocompatibility. Corros Sci $87: 89-100$

134. Fang F, Zhang X, Weckenmann A et al (2013) Manufacturing and measurement of freeform optics. CIRP Ann Manuf Technol 62(2):823-846

135. Sidpara A, Jain V (2013) Analysis of forces on the freeform surface in magnetorheological fluid based finishing process. Int $\mathbf{J}$ Mach Tools Manuf 69:1-10

136. De Wild M, Amacher F, Bradbury CR et al (2016) Investigation of structural resorption behavior of biphasic bioceramics with help of gravimetry, $\mu \mathrm{CT}$, SEM, and XRD. J Biomed Mater Res B Appl Biomater 104(3):546-553

137. Vyas N, Sammons R, Addison O et al (2016) A quantitative method to measure biofilm removal efficiency from complex biomaterial surfaces using SEM and image analysis. Sci Rep 6:32694. https://doi.org/10.1038/srep32694

138. Weckenmann A, Estler T, Peggs G et al (2004) Probing systems in dimensional metrology. CIRP Ann Manuf Technol 53(2):657-684

139. Charlton P, Blunt L (2008) Surface and form metrology of polished "freeform" biological surfaces. Wear 264(5):394-399

140. Fang F, Zhang X, Gao W et al (2017) Nanomanufacturingperspective and applications. CIRP Ann Manuf Technol 66(2):683-705

141. Schellekens P, Rosielle N, Vermeulen H et al (1998) Design for precision: current status and trends. CIRP Ann Manuf Technol 47(2):557-586

142. Brand U, Cao S, Hoffmann W et al (2001) A micro-probing system for dimensional metrology on microsystem components. In: International conference on European society for precision engineering and nanotechnology (EUSPEN). 2001, pp 266-269

143. Danzebrink HU, Koenders L, Wilkening G et al (2006) Advances in scanning force microscopy for dimensional metrology. CIRP Ann Manuf Technol 55(2):841-878

144. Seitavuopio $P$ (2006) The roughness and imaging characterisation of different pharmaceutical surfaces. Dissertation, University of Helsinki. Dissertation, University of Helsninki, Finland

145. Nemes C, Rozlosnik N, Ramsden J (1999) Direct measurement of the viscoelasticity of adsorbed protein layers using atomic force microscopy. Phys Rev E 60(2):R1166

146. Savio E, Marinello F, Bariani P, Carmignato S (2007) Featureoriented measurement strategy in atomic force microscopy. CIRP Ann Manuf Technol 56(1):557-560

147. Tamkin Sr JM (2010) A study of image artifacts caused by structured mid-spatial frequency fabrication errors on optical surfaces. Dissertation, The University of Arizona, USA

148. Rudolph W, Kempe M (1997) Trends in optical biomedical imaging. J Mod Opt 44(9):1617-1642

149. Gale MFR, Landau MR, Hogert EN et al (2003) Changing surfaces-a theoretical and experimental approach. J Opt A Pure Appl Opt 6(2):187-192 